\title{
Measurement of Green Total Factor Productivity on Chinese Pig Breeding: From the Perspective of Regional Differences
}

\section{Shen Zhong}

Harbin University of Commerce

Junwei Li

Harbin University of Commerce

Dehua Zhang ( $\nabla$ 102783@hrbcu.edu.cn )

Harbin University of Commerce https://orcid.org/0000-0003-1183-0002

\section{Research Article}

Keywords: Regional heterogeneity, Pig breeding industry, Green total factor productivity, MinDW-MML model, Pollution emissions, China

Posted Date: February 17th, 2021

DOl: https://doi.org/10.21203/rs.3.rs-201828/v1

License: (a) (1) This work is licensed under a Creative Commons Attribution 4.0 International License. Read Full License

Version of Record: A version of this preprint was published at Environmental Science and Pollution Research on January 4th, 2022. See the published version at https://doi.org/10.1007/s11356-021-179082. 
1 Measurement of green total factor productivity on Chinese

$2 \quad$ pig breeding: From the perspective of regional differences

3

4 Shen Zhong1 Junwei Li2 Dehua Zhang3*

5 Corresponding author: Dehua Zhang

61 School of finance, Harbin University of Commerce, Heilongjiang 150000, PR China;

7 102714@hrbcu.edu.cn

82 School of finance, Harbin University of Commerce, Heilongjiang 150000, PR China;

9 lijunwei@hrbcu.edu.cn

103 School of finance, Harbin University of Commerce, Heilongjiang 150000, PR China;

11 102783@hrbcu.edu.cn

12

13 Correspondence should be addressed to Dehua Zhang at the following address, phone 14 and email address:

15 Dehua Zhang

16 Institute: School of finance, Harbin University of Commerce

17 Address: No.1, Xuehai street, Songbei District, Harbin City, Heilongjiang Province,

18 China

19 E-mail:102783@hrbcu.edu.cn

20

21 Acknowledgements

22 We thank the funding sponsored by the National Social Science Foundation Program 23 of China (19BJY104). 
Abstract: China has a vast territory and abundant resources, and there are significant differences in the development of pig breeding in different regions. As the main component of Chinese residents' daily meat consumption, it is of great significance to improve people's living standards and conform to the national sustainable development strategy to raise pork production and reduce pollution emissions. In view of this, based on the minimum distance to weak efficient frontier model, this paper constructs Metafrontier-Malmquist-Luenberger index considering negative output under the common frontier to comprehensively evaluate pig breeding green total factor productivity (PBG). The results manifest that: (1) No matter under the common frontier or the group frontier, PBG presents large temporal and spatial differentiation characteristics. Compared with the eastern region and the central region, the western region has obvious advantages in PBG. (2) PBG has shown a downward trend as a whole, which is mainly due to the technical retrogression. (3) Compared with small-scale and medium-sized PBG, largescale PBG has apparent superiorities. Based on the above outcomes, combined with the actual situation of China, this paper finally raises policy recommendations for improving PBG.

Keywords: Regional heterogeneity; Pig breeding industry; Green total factor productivity; MinDWMML model; Pollution emissions; China

\section{Introduction}

Pork, as the main component of the daily meat consumption for Chinese residents, has a huge demand in the domestic market (Wu et al. 2002; Zhou et al. 2007; Wang et al. 2016; Leng et al. 2017). At the same time, with the rapid rise in pork prices, China's live hog supply fluctuated greatly (Guevarra et al. 2019; Wang et al. 2020). In order to ensure the demand of Chinese people for pork, this problem can be solved mainly by expanding the hog production scale and improving pig production efficiency (Humphrey and Schmitz 2010; Kaplinsky 2014). This article measures the pig breeding green total factor productivity (PBG) in China to improve the production efficiency of hog breeding.

There are two primary phenomena in the process of pig breeding: Firstly, the development of pig breeding industry in different parts of the country exists significantly difference (Abdalla et al. 1995; Falavigna et al. 2013). There are obvious unlikeness in traffic accessibility, rural human capital level, breeding technology services, biogas projects, urbanization level and feed price in different localities (Evans 1984; Adams 1994; Ernst 1998; Yue et al.2017). The eastern region has developed transportation and easy industrial agglomeration (Managi and Kaneko 2006; Xiao et al. 2012); the central region has an ascendant geographical location and is a traffic fortress for population mobility (Zhang et al. 2015; Yuan et al. 2017); the western region has superior environmental conditions, with low labor cost and feed transportation cost (Yue et al. 2014; Wang et al. 2015; Zhang et al. 2016). With the gradual implementation of the policy of "importing hogs from the south to the north" and the differences in environmental carrying capacity, feed resources and local breed resources in different regions, there are apparent distinctions in pig breeding industry among the three regions (Qiao et al. 2011; Zhao et al. 2015). Secondly, pollutants are generated during hog breeding (Shortle 1998; Burkholder 2007). According to the World Bank's estimation, even if only $10 \%$ of livestock manure and urine enter the water body with surface runoff due to stacking or overflowing, the eutrophication contribution rates of ammonia and phosphorus can reach 10\%-20\% (World Bank 2005). Pathogenic microorganisms and heavy metal elements in wastes can also spread diseases through environmental pollution (Segerson 1998; Campagnolo 2002; Fraison 2013). Thus, this text uses the minimum distance to weak efficient frontier- 
Metafrontier Malmquist Luenberger (MinDW-MML) model to comprehensively analyze the green total factor productivity (GTFP) of China's pig breeding industry from 2004 to 2018 by adding negative output under the condition of considering the regional heterogeneity.

The second and third parts of this article respectively introduce the study situation of relevant literature, and theoretical basis, including the primary sources of input-output variables and data. Empirical analysis is explained in the fourth part, and the fifth part is the conclusion and related policy suggestions.

\section{Literature review}

Paul D.Soloway (2004) research shows that after the 1980s, the emergence of new technologies and the increase of pig breeding specialization stimulated the continuous expansion of pig farms in the United States. With the decline in hog prices and pork prices, a large number of small producers were eliminated by the market, and the remaining producers further expanded their scale to reduce costs. As a result, the number of pig farms declined and the scale became larger. The geographical location of pig production also began to gradually tend to concentrate. Piot-Lepetit et al. (2005) conducted a study on the production efficiency of the French pig breeding industry. The results revealed that the increase of pig productivity from 1996 to 2001 was mainly attributed to technological progress, and the government's policy intervention did not improve the pig productivity. Onyenweaku and Effiong (2005) measured the technical efficiency and influencing factors of Nigerian pig production in 2004 by Stochastic Frontier Analysis (SFA) method. The results proved that breeding experience, farm size and gender of breeding members had vital effects on pig production, while farmers' credit, age, education level and family size had no significant impact on pig production efficiency. Key and McBride (2008) conducted an in-depth and systematic study on pig production efficiency in the United States from 1992 to 2004. The results demonstrated that most American farms adopted specialized production modes, with larger farms and fewer numbers. American breeding farms generally adopt professional fattening technology to improve pig production efficiency. In the past, there is a lack of research on the large sample data of Chinese pig breeding in recent years.

For the calculation of agricultural efficiency, most of the existing study methods focus on SFA, traditional Data Envelopment Analysis (DEA), Directional Distance Function (DDF) model, and Slack Based Measure (SBM) model. Ali et al. (2000) thought that efficiency was the combined result of transmission efficiency, utilization efficiency and distribution efficiency. SFA needs to preset a certain function form, but it can separate statistical error and technical inefficiency. Kaneko et al. (2004) evaluated the agricultural water use efficiency in various Chinese provinces based on SFA. The results indicated that there was a big gap between agricultural water use efficiency and production technology efficiency. The factors affecting the efficiency mainly included climate, soil and other natural conditions, as well as infrastructure construction. However, although SFA method can calculate the efficiency through the partial differential method, it cannot reasonably control the input and output variables and the endogenous problems. It has the disadvantage of needing to set a reasonable production function (Simar and Wilson 1998). Lilienfeld and Asmild (2007) used the traditional DEA method to measure the efficiency and compared the difference with SFA on efficiency. It was concluded that DEA efficiency was easily affected by the input and output in abnormal years. Sueyoshi and Goto (2012) used the traditional DEA method to measure the efficiency level of the power industry. Traditional DEA has nondynamic characteristics (Simar and Wilson 2000; Mei et al. 2015). Njuki et al. (2016) used greenhouse gases as pollutants and calculated the pig breeding efficiency of farms in the eastern United States by 
DDF model. It was found that the production efficiency of large farms was higher than that of small farms. However, DDF model cannot calculate the improvement amount and the unreasonable problem of weak disposal of undesired output. Du et al. (2017) used the SBM model to find that coastal areas are more suitable for developing small-sized and medium-sized breeding. The northeast area in China is more suitable for developing large-scale breeding, the central area is more suitable for developing smallscale and middle-scale aquaculture, and the southwest area is more suitable for developing small-scale and large-scale aquaculture. Although SBM can correct the slackness problem to the greatest extent, the obtained technical efficiency can also identify the possible relaxation measurement problem of the radial model to the greatest extent (Zhou et al. 2006). However, due to the set frontier of SBM is too far, most decision-making unit (DMU) cannot catch up or reach the effective frontier in a short time, which frustrates the "enthusiasm" of catching up, and is not conducive to the overall DMU technical progress or the improvement of production efficiency (Yu et al. 2019). MinDW model has many advantages. Because MinDW model does not need to set the function form, it can overcome the limitations of SFA and other parametric methods on input and output variables and the non-dynamic problem of traditional DEA. It can conquer the problems that the DDF model cannot calculate the amount of improvement quantity and the unreasonable handling of undesired output is weak. It can also put up with the shortcomings of the traditional CCR model and the SBM method based on the slack measure that the frontier is too far, which dampens the ineffective production unit to pursue the "enthusiasm", and avoid the subjective influence of some factors on the research results, such as weight, data outliers and substantial economic fluctuations, so as to make the results more realistic (Wang et al. 2013). Therefore, this text adopts a newer MinDW model to calculate the efficiency of pig breeding.

Apostolopoulos et al. (2001) analyzed the pig production efficiency in Greece. The results proved that most of the farms in Greece were operated by households. However, the age of Greek family farmers was older and education level was lower, which led to the low production efficiency of pigs. Production efficiency is positively correlated with the number of sows, and negatively correlated with the equipment usage time. Kliebenstein et al. (2003) pointed out that large-scale breeding has high feeding technology and management skills, and the feeding materials and service fees of pigs have little impact on largescale breeding. Wopke.vander werf (2007) of Cornell University in the United States demonstrated that with the modern breeding technology being put into live pig production, the pig production efficiency and agricultural labor productivity have been improved, thus reducing labor costs and realizing scale economy. Petrovska (2011) compared and analyzed the pig production efficiency of large-scale and small-scale farms in the Republic of Macedonia by using DEA method combined survey data. The results indicated that the technical efficiency is always low from the perspective of constant returns to scale, and the education level of managers has a greater impact on whether they use new technology for production. From the above studies, it can be seen that the existing studies on pig breeding industry did not consider the importance of regional heterogeneity and environmental factors for the research of PBG under the common frontier.

To sum up, the innovation points of this paper are mainly reflected in the following three aspects: (1) In the selection of data and samples, this article selects the input and output data of the pig production from 2004 to 2018 in Chinese 17 major pig producing areas. Compared with the previous research data, the time span is longer, the year is newer, and it is more suitable for the current development and change of China. It can more accurately evaluate the PBG situation of pig breeding in China's current era. (2) In terms of research methods, considering regional heterogeneity, this text constructs MinDW model based on the common frontier to evaluate PBGs of different sizes. (3) From the perspective of research, this 
paper introduces environmental factors into the evaluation system of pig breeding efficiency of different scales, adding negative output and highlighting the significance of environmental issues for pig breeding industry. With a view to putting forward policy suggestions for improve PBG in 17 major pig producing areas and environmental protection policy suggestions for pig breeding.

\section{Methodology}

\subsection{MinDW under the common frontier}

Minimum distance to weak efficient frontier (MinDW) refers to the nearest distance between the evaluated DMU and the leading edge, regardless of whether its projection point at the frontier is strongefficient or weak-efficient. It was first proposed by Briec 1999 and Charnes et al. 1996, which method can be expressed as $n+m$ linear programming ( $n$ is the number of input indicators, $m$ is the number of output indicators), assuming the input variable is $x$ and the output variable is $y$ : $\max \beta_{z}, z=1,2, \ldots, n+m$

s.t. $\left\{\begin{array}{l}\sum_{j=1}^{q} \alpha_{j} x_{i j}+\beta_{z} e_{i} \leq x_{i k}, i=1,2, \ldots, n \\ \sum_{j=1}^{q} \alpha_{j} x_{r j}+\beta_{z} e_{r} \geq y_{r k}, r=1,2, \ldots, m \\ \alpha_{j} \geq 0\end{array}\right.$

$e_{i}$ and $e_{r}$ are constants. In the programming formula, only one $e$ is equal to 1 , and the others are 0 , that is:

$e_{i}=1$ if $i=z ; \quad e_{i}=0$ if $i \neq z$

$e_{r}=1$ if $r=z-n ; e_{i}=0$ if $r \neq z-n$

The efficiency value of each model is expressed as:

$\theta_{z}^{*}=\frac{1-\frac{1}{n} \sum_{i=1}^{n} \frac{\beta_{z}^{*} e_{i}}{x_{i k}}}{1+\frac{1}{m} \sum_{r=1}^{m} \frac{\beta_{z}^{*} e_{r}}{y_{r k}}}$

The efficiency value of MinDW model is expressed as $\theta_{\max }^{*}=\max \left(\theta_{z}^{*}, z=1,2, \ldots, n+m\right)$, and the maximum efficiency value corresponds to the minimum $\beta^{*}$, that is the nearest distance to the frontier.

This text uses the MinDW model with negative output. The method can be expressed as $n+m+$ $f$ linear programming ( $n$ is the number of input indicators, $m$ is the number of expected output indicators, $f$ is the number of undesired output indicators):

$\max \beta_{z}, z=1,2, \ldots, n+m+f$ 


$$
\text { s.t. }\left\{\begin{array}{l}
\sum_{j=1}^{q} \alpha_{j} x_{i j}+\beta_{z} e_{i} \leq x_{i k}, i=1,2, \ldots, n \\
\sum_{j=1}^{q} \alpha_{j} x_{r j}-\beta_{z} e_{r} \geq y_{r k}, r=1,2, \ldots, m \\
q \\
\sum_{j=1}^{q} \alpha_{j} x_{p j}+\beta_{z} e_{p} \leq b_{p k}, p=1,2, \ldots, f \\
\alpha_{j} \geq 0
\end{array}\right.
$$

$e_{i}, e_{r}$ and $e_{p}$ are constants. In the programming formula, only one $e$ is equal to 1 , and the others are 0 , that is:

$e_{i}=1$ if $i=z ; e_{i}=0$ if $i \neq z$

$e_{r}=1$ if $r=z-n ; e_{i}=0$ if $r \neq z-n$

$e_{p}=1$ if $p=z-n-m ; e_{i}=0$ if $p \neq z-n-m$

The efficiency value of each model is expressed as:

$\theta_{z}^{*}=\frac{1-\frac{1}{n} \sum_{i=1}^{n} \frac{\beta_{z}^{*} e_{i}}{x_{i k}}}{1+\frac{1}{m+b}\left(\sum_{r=1}^{m} \frac{\beta_{z}^{*} e_{r}}{y_{r k}}+\sum_{p=1}^{f} \frac{\beta_{z}^{*} e_{p}}{b_{p k}}\right)}$

The efficiency value of MinDW model is expressed as $\theta_{\max }^{*}=\max \left(\theta_{z}^{*}, z=1,2, \ldots, n+m+f\right)$, and the maximum efficiency value corresponds to the minimum $\beta^{*}$, which means the nearest distance to the frontier.

The efficiency value of MinDW model will not be less than that of directional distance function model with any direction vector or other distance types (such as radial and SBM). In other words, the efficiency value of MinDW model is the largest. Combined with the above process, we can define the regional boundary $\left(\beta^{\text {region* }}\right)$ and the model is as follows:

$\beta^{\text {region } *}=\max \frac{1-\frac{1}{n} \sum_{i=1}^{n} \frac{\beta_{z} e_{i}}{x_{i k}}}{1+\frac{1}{m+b}\left(\sum_{r=1}^{m} \frac{\beta_{z} e_{r}}{y_{r k}}+\sum_{p=1}^{f} \frac{\beta_{z} e_{p}}{b_{p k}}\right)}$

s.t. $\left\{\begin{array}{l}\sum_{j=1}^{q} \alpha_{j} x_{i j}+\beta_{z} e_{i} \leq x_{i k}, i=1,2, \ldots, n \\ \sum_{j=1}^{q} \alpha_{j} x_{r j}-\beta_{z} e_{r} \geq y_{r k}, r=1,2, \ldots, m \\ q \\ \sum_{j=1}^{q} \alpha_{j} x_{p j}+\beta_{z} e_{p} \leq b_{p k}, p=1,2, \ldots, f \\ \alpha_{j} \geq 0\end{array}\right.$

Similarly, the efficiency value of DMU relative to the common frontier $\left(\beta^{\text {meta* }}\right)$ can be obtained by the 
following model:

$$
\beta^{\text {meta* }}=\max \frac{1-\frac{1}{n} \sum_{i=1}^{n} \frac{\beta_{z} e_{i}}{x_{i k}}}{1+\frac{1}{m+b}\left(\sum_{r=1}^{m} \frac{\beta_{z} e_{r}}{y_{r k}}+\sum_{p=1}^{f} \frac{\beta_{z} e_{p}}{b_{p k}}\right)}
$$

$$
s . t .\left\{\begin{array}{l}
\sum_{j=1}^{q} \alpha_{j} x_{i j}+\beta_{z} e_{i} \leq x_{i k}, i=1,2, \ldots, n \\
\sum_{j=1}^{q} \alpha_{j} x_{r j}-\beta_{z} e_{r} \geq y_{r k}, r=1,2, \ldots, m \\
\sum_{j=1}^{q} \alpha_{j} x_{p j}+\beta_{z} e_{p} \leq b_{p k}, p=1,2, \ldots, f \\
\alpha_{j} \geq 0
\end{array}\right.
$$

Finally, in the common frontier model, the technology gap ratio (TGR) is equal to the ratio of the efficiency value of the common frontier to the efficiency value of the group frontier. The formula is as follows:

$T G R^{\text {MinDW }}=\frac{\beta^{\text {meta* }}}{\beta^{\text {region } *}}$

$\beta^{\text {region* }}$ and $\beta^{\text {meta* }}$ represent the optimal solution of formula (7) and formula (8), respectively. TGR is used to measure the distance between the optimal production technology and the potential optimal technology of a group, and whether there are any differences in PBG under different groups. The closer the TGR is to 1, the closer the technology level is to the optimal potential technology level. Conversely, it is the larger the gap between the technology level and the potential optimal technology level.

\subsection{Metafrontier-Malmquist-Luenberger index and its decomposition}

Malmquist productivity index is widely used in the study of dynamic efficiency change trend, and has good adaptability to multiple input-output data and panel data analysis. The actual production process often contains unexpected output. After Chung et al. (1997) proposed Malmquist-Luenberger (ML) index, any Malmquist index with undesired output can be called ML index. Oh (2010) constructed the GlobalMalmquist-Luenberger index. All the evaluated DMUs are included in the global reference set, which avoids the phenomenon of infeasible solution in VRS and "technology regression". The global reference set constructed in this article is as follows:

$U^{G}(x)=U^{1}\left(x^{1}\right) \cup U^{2}\left(x^{2}\right) \cup \ldots \cup U^{T}\left(x^{T}\right)$ and

$$
U^{t}\left(x^{t}\right)=\left\{\left(y^{t}, b^{t}\right) \mid x^{t} \text { can produce }\left(y^{t}, b^{t}\right)\right\}
$$

This article takes $M M L$ index as the PBG. 


$$
\begin{aligned}
M M L_{t-1}^{t}= & \sqrt{\frac{1-M_{t-1}\left(x^{t}, y^{t}, b^{t} ; y^{t},-b^{t}\right)}{1-M_{t-1}\left(x^{t-1}, y^{t-1}, b^{t-1} ; y^{t-1},-b^{t-1}\right)} \times \frac{1-M_{t}\left(x^{t}, y^{t}, b^{t} ; y^{t},-b^{t}\right)}{1-M_{t}\left(x^{t-1}, y^{t-1}, b^{t-1} ; y^{t-1},-b^{t-1}\right)}} \\
= & \sqrt{\frac{1-M_{t-1}\left(x^{t-1}, y^{t-1}, b^{t-1} ; y^{t-1},-b^{t-1}\right)}{1-M_{t}\left(x^{t-1}, y^{t-1}, b^{t-1} ; y^{t-1},-b^{t-1}\right)} \times \frac{1-M_{t-1}\left(x^{t}, y^{t}, b^{t} ; y^{t},-b^{t}\right)}{1-M_{t}\left(x^{t}, y^{t}, b^{t} ; y^{t},-b^{t}\right)}} \\
& \times \frac{1-M_{t}\left(x^{t}, y^{t}, b^{t} ; y^{t},-b^{t}\right)}{1-M_{t-1}\left(x^{t-1}, y^{t-1}, b^{t-1} ; y^{t-1},-b^{t-1}\right)}
\end{aligned}
$$

233

Further decompose the $M M L$ index into efficiency change $(E C)$ and technology change $(T C)$.

$T C_{t-1}^{t}=\sqrt{\frac{1-M_{t-1}\left(x^{t-1}, y^{t-1}, b^{t-1} ; y^{t-1},-b^{t-1}\right)}{1-M_{t}\left(x^{t-1}, y^{t-1}, b^{t-1} ; y^{t-1},-b^{t-1}\right)} \times \frac{1-M_{t-1}\left(x^{t}, y^{t}, b^{t} ; y^{t},-b^{t}\right)}{1-M_{t}\left(x^{t}, y^{t}, b^{t} ; y^{t},-b^{t}\right)}}$

$E C_{t-1}^{t}=\frac{1-M_{t}\left(x^{t}, y^{t}, b^{t} ; y^{t},-b^{t}\right)}{1-M_{t-1}\left(x^{t-1}, y^{t-1}, b^{t-1} ; y^{t-1},-b^{t-1}\right)}$

Where $\left(x^{t-1}, y^{t-1}, b^{t-1}\right)$ and $\left(x^{t}, y^{t}, b^{t}\right)$ represent the input, desired output and undesired output of t-1 and t, respectively. $T C_{t-1}^{t}$ and $E C_{t-1}^{t}$ are the contribution to $\mathrm{PBG}$ raise of DMU's technical progress and efficiency improvement from $\mathrm{t}-1$ to $t$, respectively. The higher the value is, the larger the contribution is. The $M M L$ index is recorded as $M I$ and the value of $M I$ is the PBG. The green total factor productivity index of pig breeding under the common frontier and group frontier are as below:

$$
m M I_{t-1}^{t}=\sqrt{\frac{1-M_{t-1}^{m}\left(x^{t}, y^{t}, b^{t} ; y^{t},-b^{t}\right)}{1-M_{t-1}^{m}\left(x^{t-1}, y^{t-1}, b^{t-1} ; y^{t-1},-b^{t-1}\right)} \times \frac{1-M_{t}^{m}\left(x^{t}, y^{t}, b^{t} ; y^{t},-b^{t}\right)}{1-M_{t}^{m}\left(x^{t-1}, y^{t-1}, b^{t-1} ; y^{t-1},-b^{t-1}\right)}}
$$

$$
g M I_{t-1}^{t}=\sqrt{\frac{1-M_{t-1}^{g}\left(x^{t}, y^{t}, b^{t} ; y^{t},-b^{t}\right)}{1-M_{t-1}^{g}\left(x^{t-1}, y^{t-1}, b^{t-1} ; y^{t-1},-b^{t-1}\right)} \times \frac{1-M_{t}^{g}\left(x^{t}, y^{t}, b^{t} ; y^{t},-b^{t}\right)}{1-M_{t}^{g}\left(x^{t-1}, y^{t-1}, b^{t-1} ; y^{t-1},-b^{t-1}\right)}}
$$

For the DMUs with regional heterogeneity, we can calculate the technology gap between the group frontier and the common frontier, which is caused by the specific group institutional structure.

\subsection{Data and variables}

Based on the research of the existing literature, this text chooses five indexes to build the inputoutput indicator system. Details are as below:

(1) Piglet input: Piglet weight. The average weight of each piglet that a pig farmer buys outside or raises through his own pig.

(2) Labor input: The number of employees. The sum number of days of direct labor for agricultural employees and family employees.

(3) Capital input: Namely, expenses investment, including concentrate feed expenses, water and fuel power expenses, and medical epidemic prevention expenses. The expenses of concentrate refer to the input expenses of various kinds of concentrate actually consumed by each hog from purchase to fattening, including the total expenses of grain, soybean cake, mixed feed, plant powder and other expenses. Water and fuel power expenses includes water, electricity, coal and other fuel power expenses. 
Medical and epidemic prevention expenses include the expenses for disease prevention and control.

(4) Positive output: The output of the main products, which means the weight of each fattening pig at the time of slaughter.

(5) Negative output: Pollutant discharge.

According to the calculation method of Zuo et al. (2016),

$D A=\frac{C O D}{20}+\frac{T N}{1}+\frac{T P}{0.2}$

Where $D A$ is the discharge amount. According to the calculation method of Du et al. (2017), the specific calculation steps are as follows:

$C E=D_{A} \times C E C \times \frac{W_{A}}{W_{R}}$

$N E=D_{A} \times N E C \times \frac{W_{A}}{W_{R}}$

$P E=D_{A} \times P E C \times \frac{W_{A}}{W_{R}}$

Where $C E, N E$ and $P E$ represent the COD emission, the TN emission and the TP emission, respectively. $D_{A}$ is the average feeding days. $C E C, N E C$ and $P E C$ are the COD emission coefficient, the TN emission coefficient and the TP emission coefficient, respectively. $W_{R}$ and $W_{A}$ represent the reference weight and the actual weight, respectively.

Piglet weight, labor quantity, concentrate expenses, water and fuel expenses, medical cost, actual weight, average feeding days and main product output all came from 2004-2018 《National Compendium of Agricultural Product Expenses-Benefit Data》. The reference weight and emission coefficient are derived from the 《Discharge Coefficient Manual》 released by the Office of the First National Pollution Source Census Leading Group. And the proportion of water feces and dry feces in each province was referred to Du et al. (2017). Meanwhile, according to the above two data on the definition of scale, this text will divide live pig breeding scale into three types: large scale, middle scale and small scale. Smallscale refers to 30-100 farming households listed annually. Middle scale refers to the annual output of 100-1000 scale farms. Large scale refers to more than 1000 farming area.

In the sample choice, this text chooses 17 major producing provinces of the 《Plan of National Pig Production Development (2016-2020)》 pig advantage producing areas as the study samples. It is separated into three areas: The Eastern Area (Jiangsu, Zhejiang, Guangdong, Liaoning, Hebei, Shandong), the Central Area (Anhui, Hubei, Hunan, Heilongjiang, Jilin, Henan), and the Western Area (Guizhou, Guangxi, Chongqing, Sichuan, Yunnan). 


\subsection{The overall change of PBG in China}

292

293

294
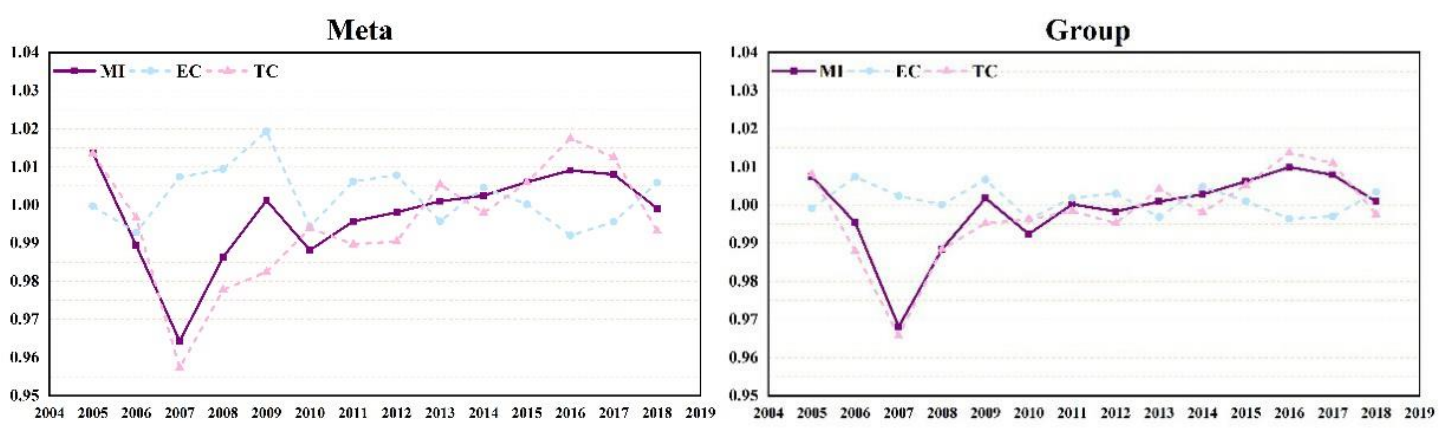

Fig.1. China's PBG and its decomposition target during 2004-2018.

It can be seen from Fig. 1 that the overall fluctuation trend under the common frontier and the regional frontier is basically the same. The fluctuation amplitude under the common front is larger. From 2005 to 2007 and from 2009 to 2010, PBG declined twice, with the larger decline in the former $(3.57 \%$ declined under the common frontier and 3.19\% declined under the group frontier), while the smaller decline in the latter $(1.18 \%$ declined under the common frontier and $0.76 \%$ declined under the group frontier). This was mainly due to the outbreak of blue ear disease in 2006, the global financial crisis in 2008, the outbreak of influenza A (H1N1) virus in 2009 and other causes. The significant fluctuation of PBG in 2007 indicates that the prevention and control of pig epidemic situation and the stability of the market have an extremely significant impact on pig production. 2007 is the turning point of the development of China's pig industry. Before 2007, the fluctuation of each index was large. After the downturn of animal husbandry in 2007 , the implementation of relevant national policies had a significant impact on the whole country. After 2007, China's pig market began to stabilize. Therefore, the government should increase the prevention and control of pig diseases, enlarge the research and introduction of technology, and stabilize the pork price.

In 2016, both PBG and TC reached the peak. PBG increased by $0.91 \%$ and TC increased by $1.74 \%$ under the metafrontier. Then, PBG increased by $0.99 \%$ and TC increased by $1.37 \%$ under the group frontier. After 2016, the PBG has shown a downward trend, mainly due to the upsurge of investment in pig farming by major enterprises in 2016, which saw hog price spiral through year-round highs. In 2017 , piglet sales and pork prices all fell to varying degrees. The price of piglets is affected by pig price, weather factors and farmers' mentality of filling hurdles. Since the first case of African swine fever was found in China on August 3, 2018, African swine fever has spread rapidly in China. There was a slight decrease in 2017 and 2018 from the boom to the freezing point. The main reason for the sharp decline in investment is the impact of the economic environment. Most China's enterprises have a tight capital chain, and large enterprises have expanded the proportion of breeding in the "company + farmer" mode, and purchased a large number of piglets for stocking. In summary, PBG showed a downward trend in the past 15 years, with a decrease of $0.27 \%$ in the common frontier and $0.14 \%$ in the regional frontier. 


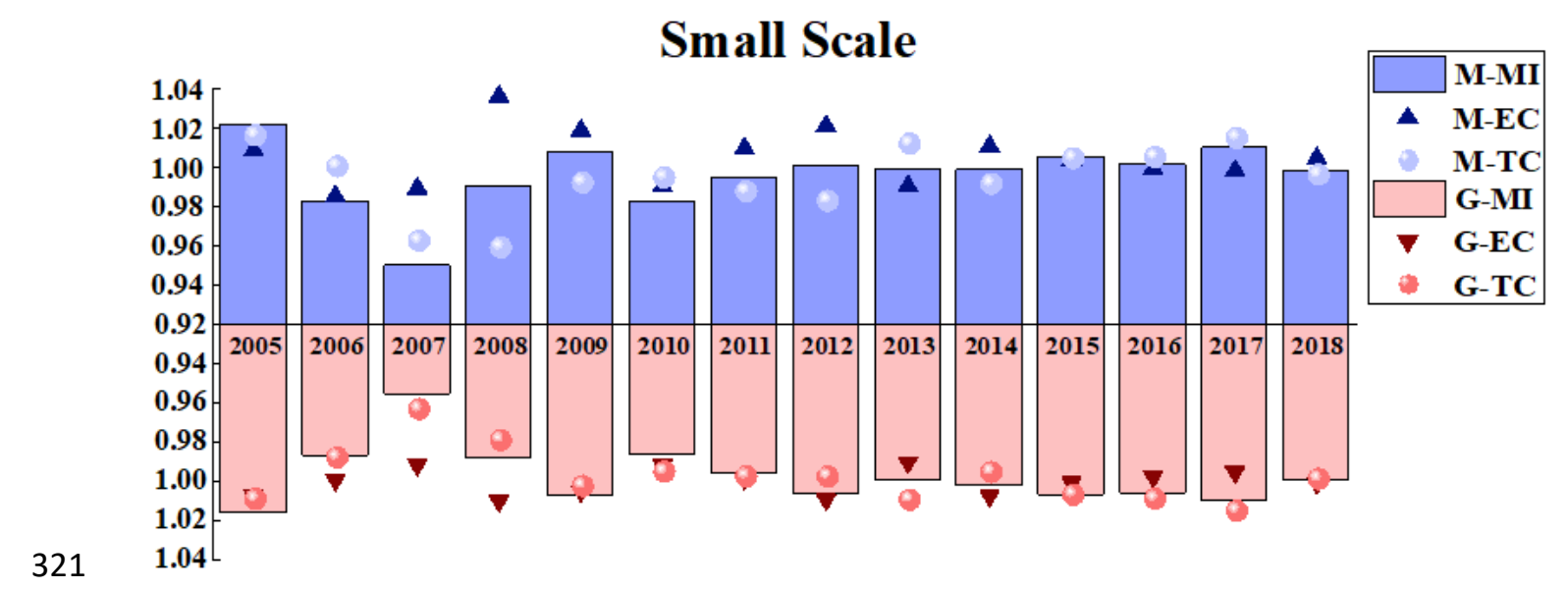

Middle Scale

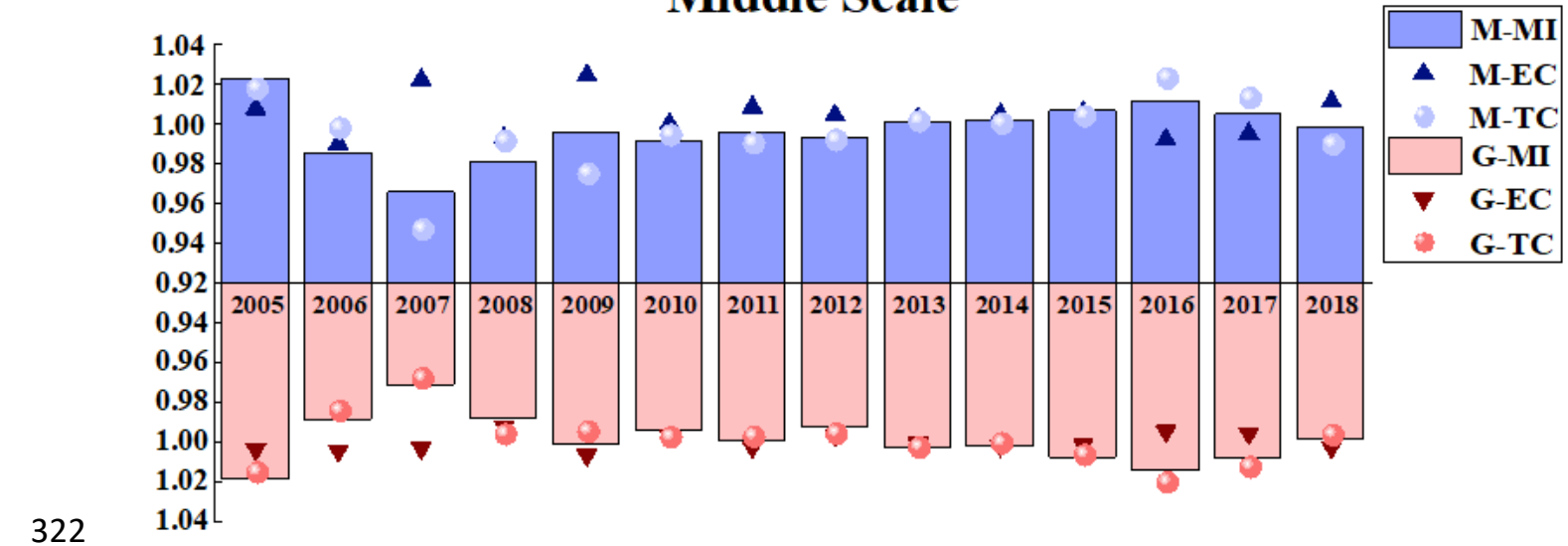

\section{Large Scale}

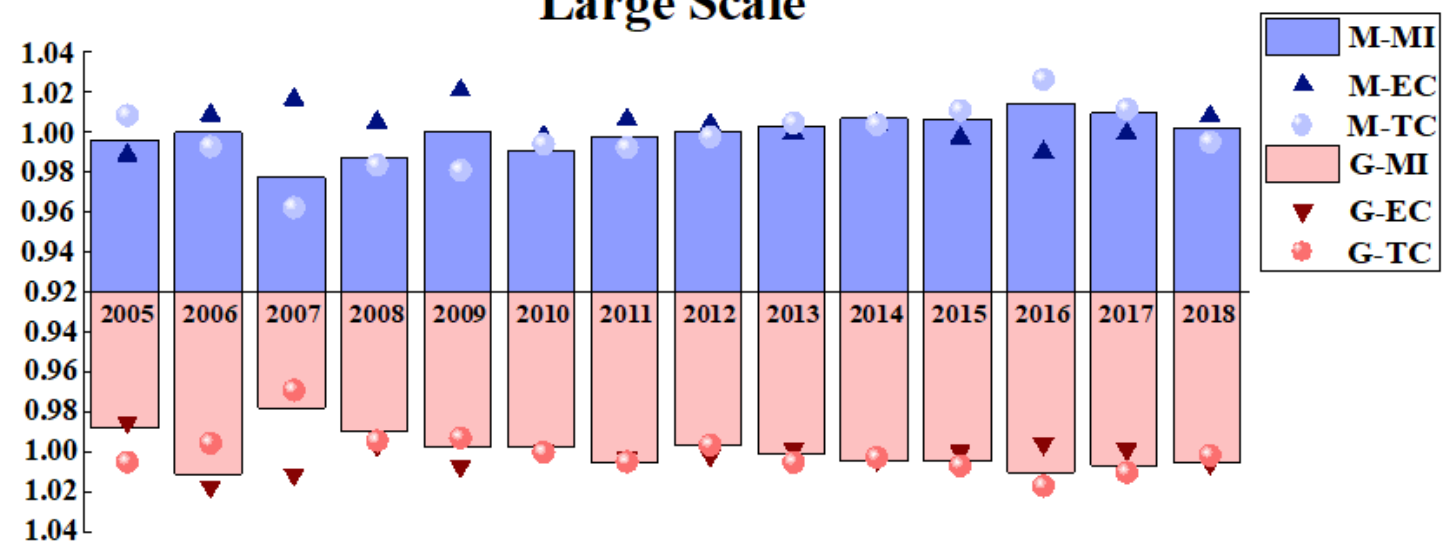

Fig.2. China's various-sized PBG and its decomposition target during 2004-2018.

As shown in Fig.2, the fluctuation trends of PBG and TC are similar under the common frontier and group frontier. The fluctuation range of EC is larger under the metafrontier. In 2008, the small-scale EC increased and TC decreased, while in the medium-sized and large-scale, TC rose and EC declined. This is mainly because after the Ministry of Agriculture released the "Animal manure resource utilization action plan (2017-2020)", the nation promoted the resource utilization of livestock and poultry breeding wastes, accelerated the transformation and upgrading of animal husbandry, and constructed a new pattern of sustainable development of farming-breeding combination and farming-pastoral cycle, which improved the standardized breeding technology. In the "Lament" voice of prohibition and restriction breeding, a new way is pointed out for farmers: as long as the waste resources of livestock and poultry 
can be effectively utilized, the forbidden areas such as water sources can be far away, and the efficient green ecological breeding industry can be developed, pigs can not only be raised, but also own the support of the government. China's environmental protection policy continues to tighten. Driven by both policies and technologies, green ecological transformation and promoting large-scale modern farming must be the theme of the future pig industry. Combined with the actual situation in China, the first half of 2014 and 2015 are the golden opportunities for pig breeding industry to expand against the trend. In 2016, it will make a rich profit, which is the due return of gold opportunities. In 2017, it will earn the return of the expansion of the trend. Of course, there is certainly no downside to profit. 2018 is a loss period, making PBG decline.

Large-scale PBG is higher than medium and small scale. The construction of large-scale farm takes about one year. It takes about two years to introduce sows to produce piglets, and then to develop piglets into commercial pigs. Without sows, there would be no piglets, and the supply of subsequent commercial pigs would not go up. Since 2012, the reason for technological progress may be that large-scale pig farms gradually introduced to foreign countries and learned the technology to adapt to large-scale pig farms in practice. However, with the scale expansion of pig farms, exceeding the appropriate scale, the unreasonable resource allocation has begun to show the characteristics of decline in technical efficiency. The State Council's "13th Five-Year Plan" on ecological and environmental protection requires that the relationship between pig production and environmental protection should be well handled through "prohibition, restriction, transfer and governance". By the end of 2017, various regions should close or relocate pig farms and specialized breeding households in the forbidden areas according to law. From 2017 to 2018, both the quantity and the price of live pigs in China were low, reflecting the enthusiasm of pig farmers to fill the hurdle is not high, but the enthusiasm is gradually rising.

As can be seen from Fig.3, under the common frontier, the PBG of Guizhou (0.9880), Shandong (0.9942), Jilin (0.9950) and Anhui (0.9957) is lower, while Hunan (1.0035), Guangdong (1.0033) and Hubei (1.0030) are higher, all above 1, showing positive growth. Under the regional frontier, the PBG of Heilongjiang (0.9930), Shandong (0.9935), Guizhou (0.9939), Jilin (0.9947) is lower, while Guangxi (1.0066), Guangdong (1.0039), Yunnan (1.0014) and Hubei (1.0012) are higher, all exceeding 1, indicating positive growth. Whether in the common frontier or group frontier, the PBG of Guizhou, Shandong and Jilin are all reciprocal, and the growth is negative. TC value is also less than 1, indicating that the level of environmental protection farming technology in these areas needs to be improved. Guangdong and Hubei ranked the top four of the two frontiers, demonstrating that the pig farms in these areas have been upgraded in animal welfare, environmental protection treatment, technological innovation and other aspects, providing a transformation and upgrading scheme for China's modern agriculture once again. In addition, some pig breeding enterprises have gradually formed a threedimensional sales system of "online e-commerce + offline supermarket + high-end experience store". The innovative attempt to inject Internet gene into pork sales channels is also of great significance to China's pig industry. Although the tax on solid and water pollution increases the economic burden of the farms, it can promote the reduction of emissions from the source, strengthen the resource utilization of manure, boost the sustainable development and bring long-term economic benefits. Under the heavy pressure of environmental policies, some local governments have excessive demolition and "one size fits all" phenomenon. In this regard, the leaders at all levels of the Ministry of Agriculture have repeatedly stressed the need to standardize the zoning of prohibited breeding areas, prevent the blind expansion of captivity breeding areas, simply close down the farms, and vigorously stabilize the pig industry. 

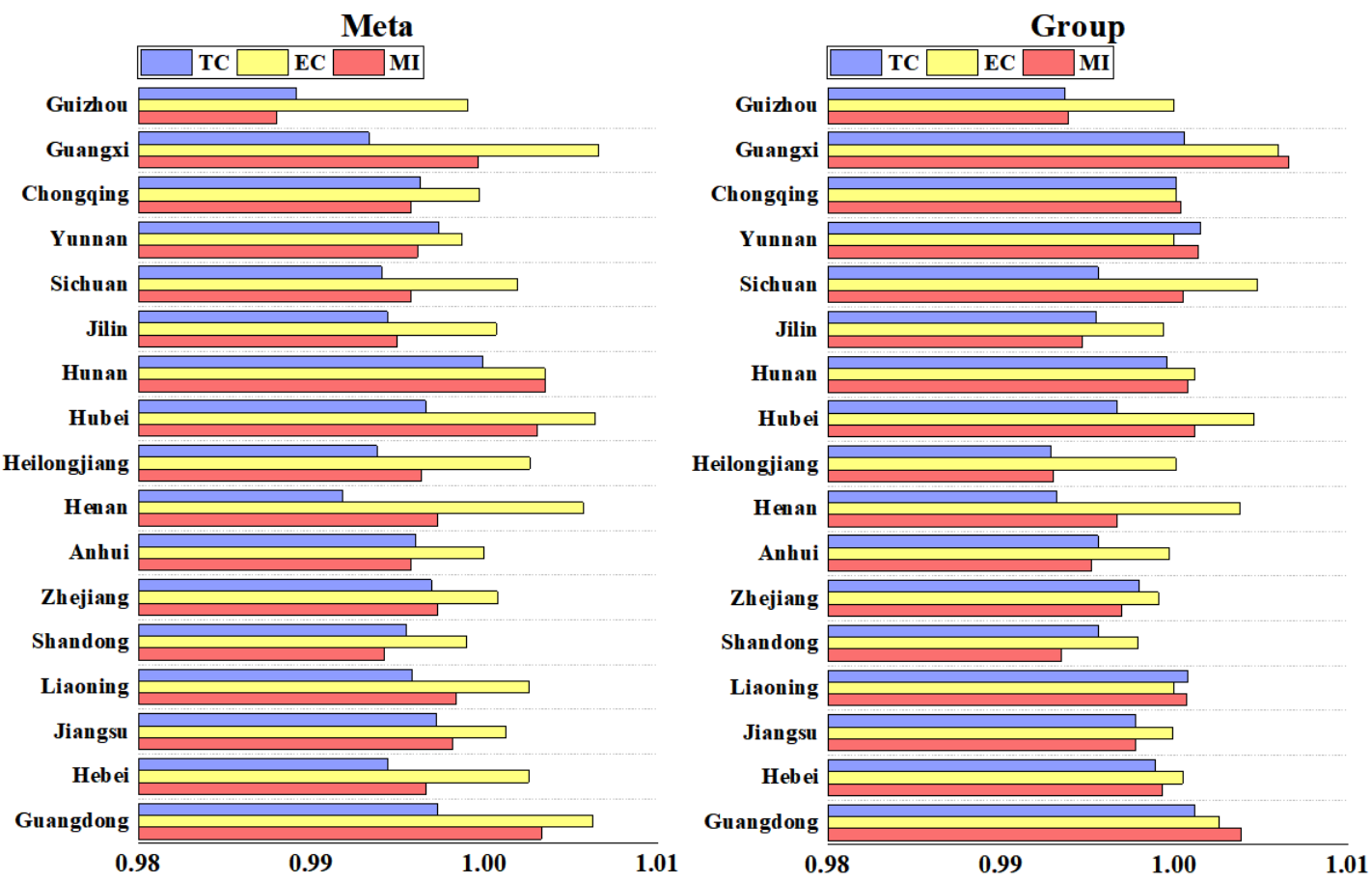

Fig.3. PBG and its decomposition target in different provinces.

As shown in Fig.4, under the metafrontier, the small-scale (0.9960) PBG is the lowest, the mediumsized (0.9968) is the second, and the large-scale (0.9992) is the highest. The values of three-scales TC are all negative growth, and of $\mathrm{EC}$ are positive growth. Under the regional frontier, small-scale PBG fell $0.26 \%$, medium-sized PBG fell $0.11 \%$, and large-scale PBG fell $0.04 \%$. Under the group frontier, the PBG is higher than that under the common frontier, and the average annual PBGs of the whole country are 0.9986 and 0.9973 respectively, which are all negative growth. This is mainly because China has only begun to implement the promotion of low-carbon farming technology in recent three years. However, promotion takes time. Most areas still adopt traditional breeding methods. The overall application level of modern environmental protection breeding technology in China is low, resulting in low PBG in the whole country. Therefore, it is necessary to vigorously improve the environmental protection technology level of pig breeding. Whether grouped or not, small-scale farming in Hunan, medium-scale farming in Guangdong, and large-scale farming in Jiangsu, Hubei, Chongqing, Yunnan and Guangdong are all outstanding. Sichuan is a traditional pig province with rapid development of pig industry, but the pig industry in Northeast, Henan, Shandong and other places develops more rapidly. Compared with them, there is a certain gap in large-scale breeding, selection of excellent varieties and pork quality in Sichuan, resulting in negative PBG. 

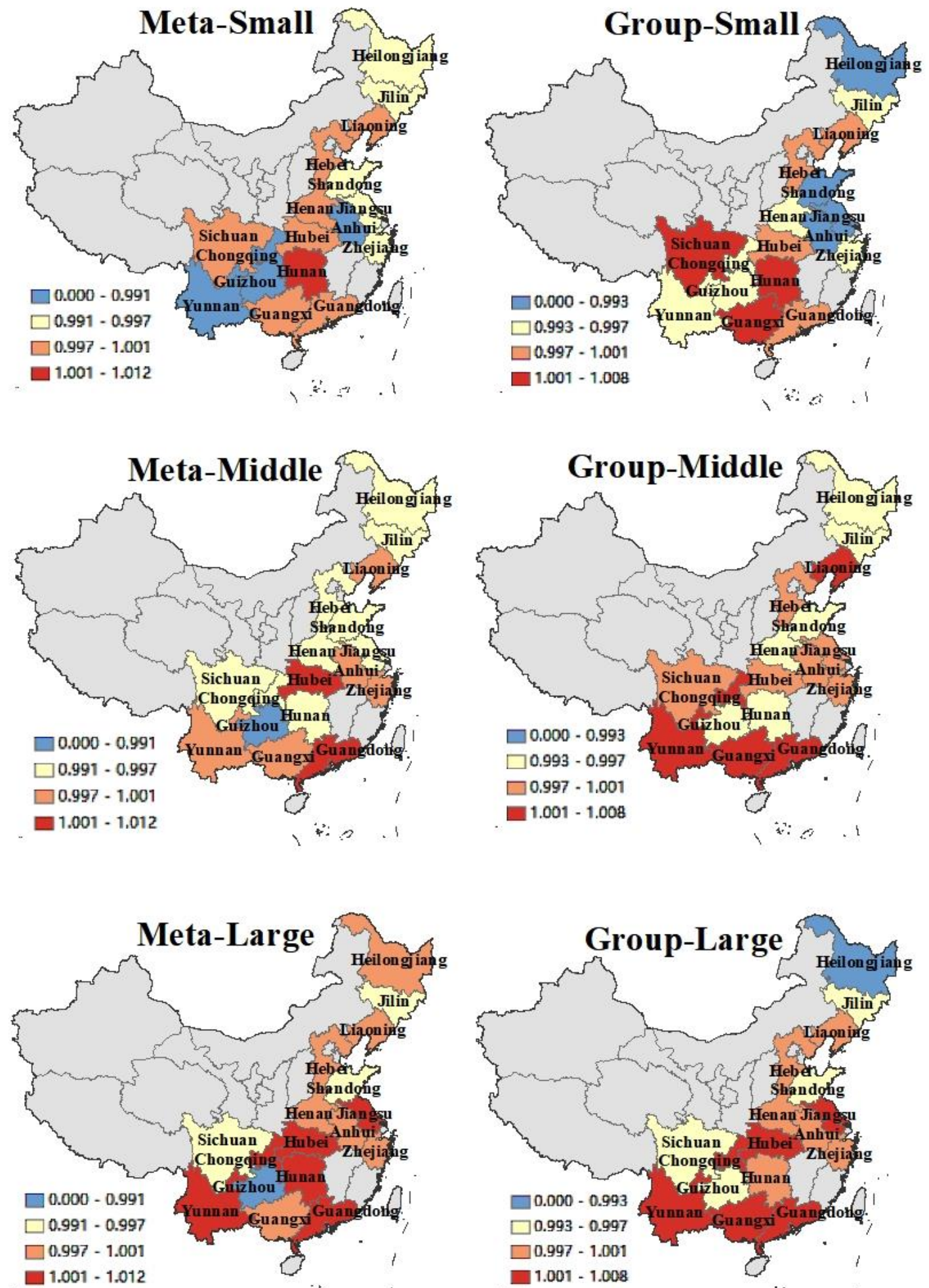

Fig.4. Various-scaled PBG in different provinces 


\section{TGR}

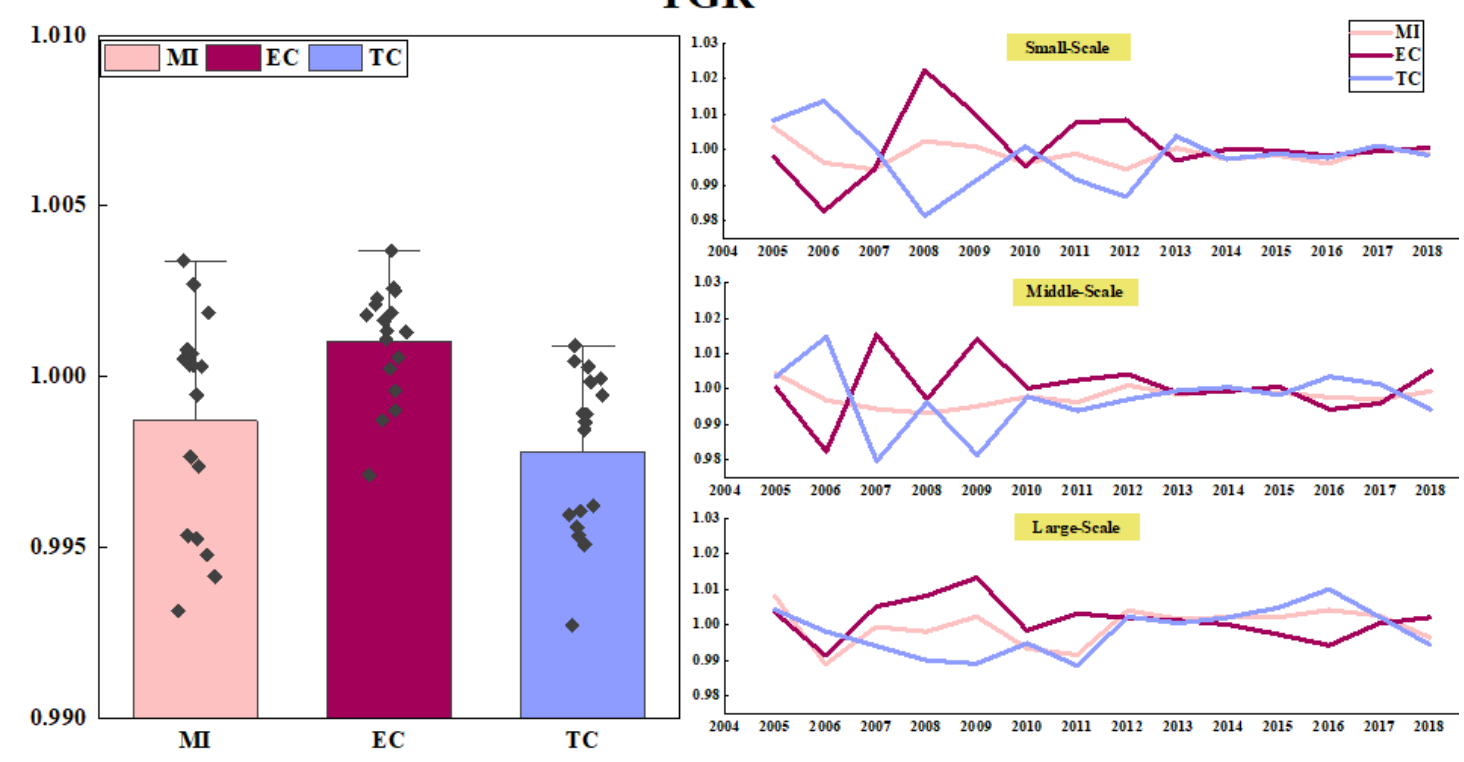

Fig.5. TGR in general and different scale during 2004-2018.

As shown in Fig.5, from the perspective of time, the fluctuation range of TGR was relatively large before 2012, gradually flattened from 2012 to 2016, hovering around 1, at a high level. It indicates that the frontier of regional frontier is closer to the common frontier. But after 2016, the volatility began to increase gradually. This is mainly because 2017 is a year of ups and downs for China's pig breeding industry. Whether it is the fluctuation of pig prices in the market, the promotion of modern agriculture in policy, the full implementation of prohibition breeding and restriction farming, the innovation and development of breeding technology, or the large-scale expansion at the enterprise level, all involve every enterprise, every practitioner, and even every consumer in the pig industry chain. On January 1, 2018, the "Environmental Protection Tax Law" was formally implemented and the implementation of environmental protection tax law is a severe test for the breeding industry. The tax law stipulates the main pollution emitted by pig farms with 500 or more pigs are water pollutants and solid pollutants. According to the relevant investigation, a pig farm with 500 pigs on hand in Guangdong should pay the tax of at least 4.6 yuan per pig. In a short time, this will cause some harm to the pig industry. On the whole, the technology presents the trend of regression, and technical efficiency is an increasing trend. The reason may be that with the development of large-scale pig breeding, the technology updates slowly, and the technology adapted to small-scale pig farm cannot adapt to large-scale production, so it is manifested as technological regression. The reason for the progress of technical efficiency is that with the expansion of pig farm scale, it presents the characteristics of scale economy.

\subsection{The change of PBG in different regions}



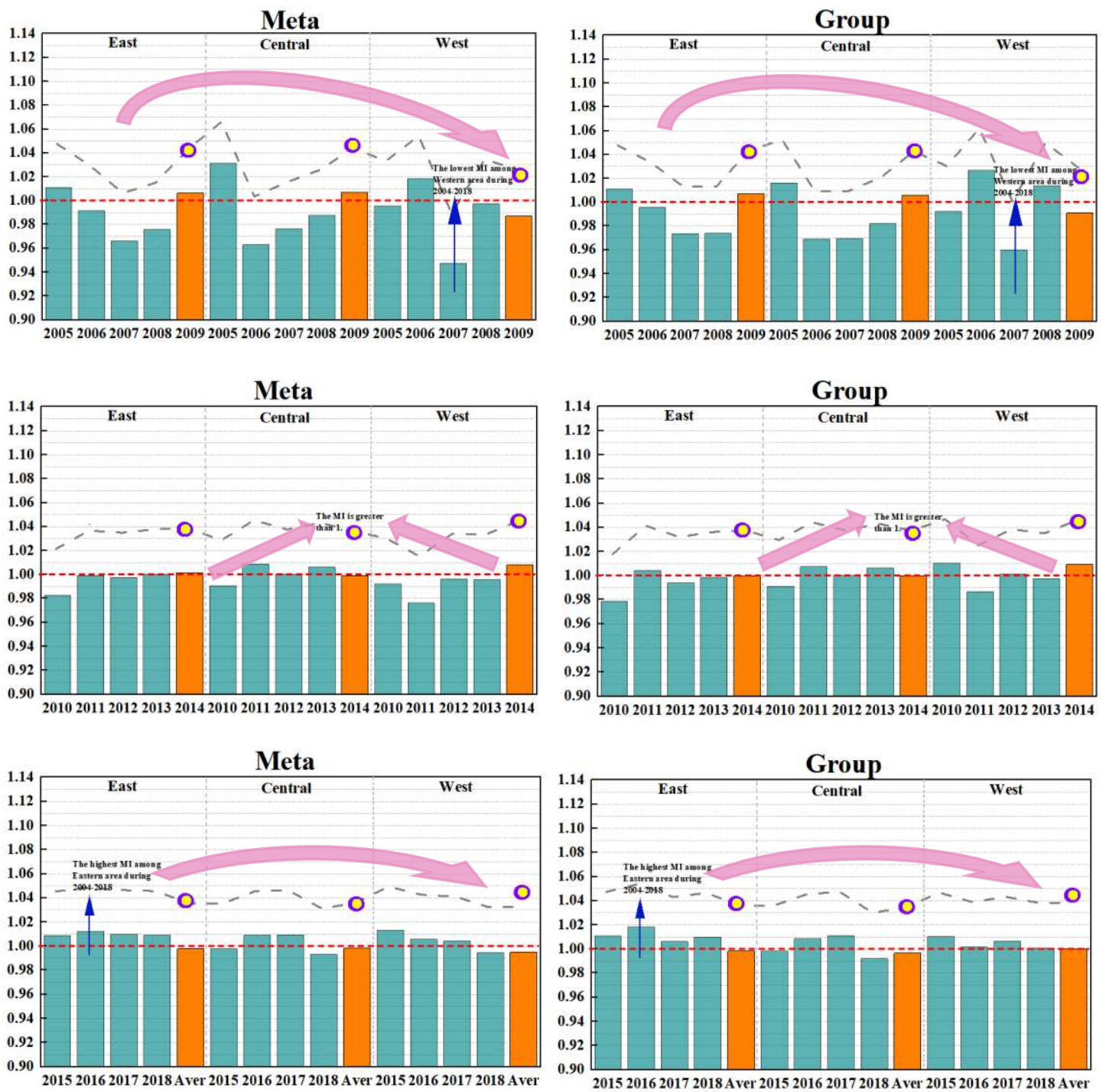

Fig.6. PBG in three regions during 2004-2018

According to Fig.6, in the past 15 years, PBG fluctuated greatly from 2004 to 2009 and remained stable after 2015, with the lowest PBG in 2007 and the highest PBG in 2016. Under the common frontier, PBG decreased by $3.57 \%$ in 2007 and increased by $0.91 \%$ in 2016. Under the regional frontier, PBG decreased by $3.19 \%$ in 2007 and increased by $0.99 \%$ in 2016 . Obviously, the degree of decline is greater. The weak positive growth in some specific years does not make up for the negative growth in most years, so the average PBG is negative. The eastern region and western regions have higher PBG under the regional frontier, while the central region has higher PBG under the common frontier. This shows that the central region still relies on traditional breeding technology to a large extent, and the level of lowcarbon pig breeding technology is low. In recent years, the development of pig industry is not optimistic, and the PBG generally shows a negative growth. The reason is that the periodic imbalance between supply and demand in 2017 has supported the rapid recovery of pig market price. Farmers continue to be reluctant to sell and support the price, the intention of slaughterhouse to reduce the price is obvious, and the domestic pig market supply and demand game situation is intensified. In some areas, the impact of Vietnam pig is huge, and the price has decreased. In terms of demand, the pork sales of northern enterprises are not ideal and the pork price is difficult to raise. The cost pressure and the intention of 
price reduction is heavy. The production of southern pickled food is gradually opening up, and the growing demand will also have a certain stimulating effect. In 2018, pig prices continued to decline. This mainly because, on the one hand, scale farms are still expanding, and the concentration on pig breeding market is gradually increasing, on the other hand, in the context of sufficient pig supply, the demand follows up slowly, the market is oversupply, and the overall pig price is declining. Although China's PBG showed a downward trend after 2016, it is expected to recover slowly over time and rise steadily.
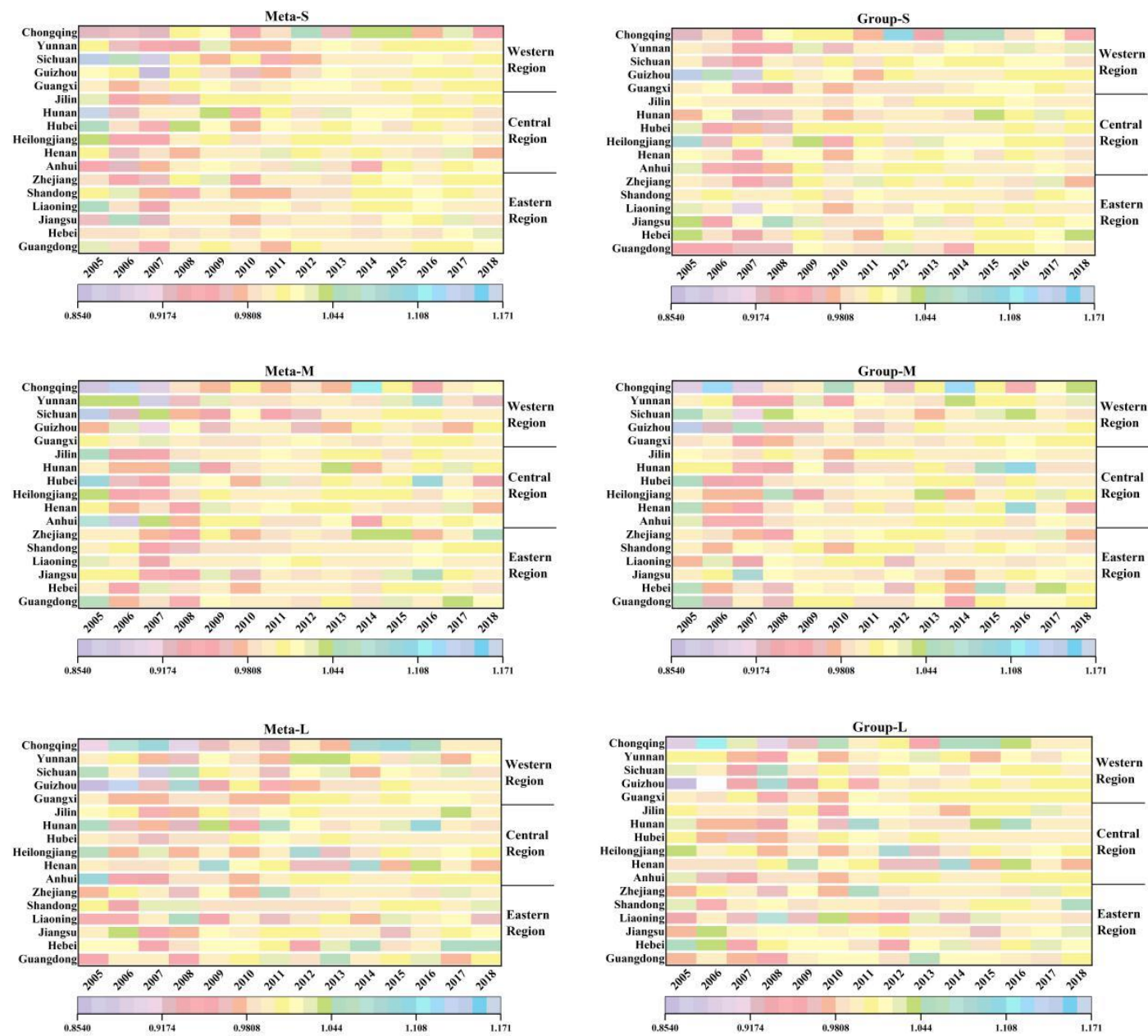

Fig.7. Three-sized PBG in three regions during 2004-2018.

As can be seen from Fig.7, the three-scaled PBG under the regional frontier has a larger fluctuation range than that under the common frontier, and the fluctuation trend is the same. Under the metafrontier, the PBG of the central region is higher than that of the eastern and western regions, and the large-scale PBG is higher than that of the medium-sized and small-scale, but there is little difference among the three scales. After 2016, PBG showed a downward trend. Since 2017, China has paid more and more attention to the environmental protection. Strict control of the environment problems of the aquaculture industry has made it difficult to move forward and narrow the scale. In 2017, raising farm animal welfare has become an essential issue for the pig industry. On October 12, 2017, the World Farm Animal Welfare Conference was held in China. This was the first grand meeting held by the Food and Agriculture Organization of the United Nations for farm animal welfare. The first congress was held in China, which attracted more attention from Chinese breeding enterprises and scientifically understand farm animal 
welfare, and realized the positive role of practical animal welfare practice in the farming development and pork quality. After the meeting, more and more Chinese breeding enterprises began to practice animal welfare to ensure the sustainable development of breeding. Since the national regulation of implementing environmental protection farming in 2017, Chongqing in the western region, Henan in the central region and Jiangsu in the eastern region will complete the task indicators ahead of schedule by 2018. Anhui and Hubei in the central region will also complete the task of banning breeding by the end of the year. Guangdong in the eastern region and other places will also complete the relevant work at the beginning of 2018. After the ban, the next step is to promote the recycling of livestock and poultry manure. Many small-scaled and medium-sized farmers have not survived the difficulties, forced to give up pig breeding. Before withdrawing from the market, they will inevitably put live pigs into the market, resulting in a decline of pig prices.
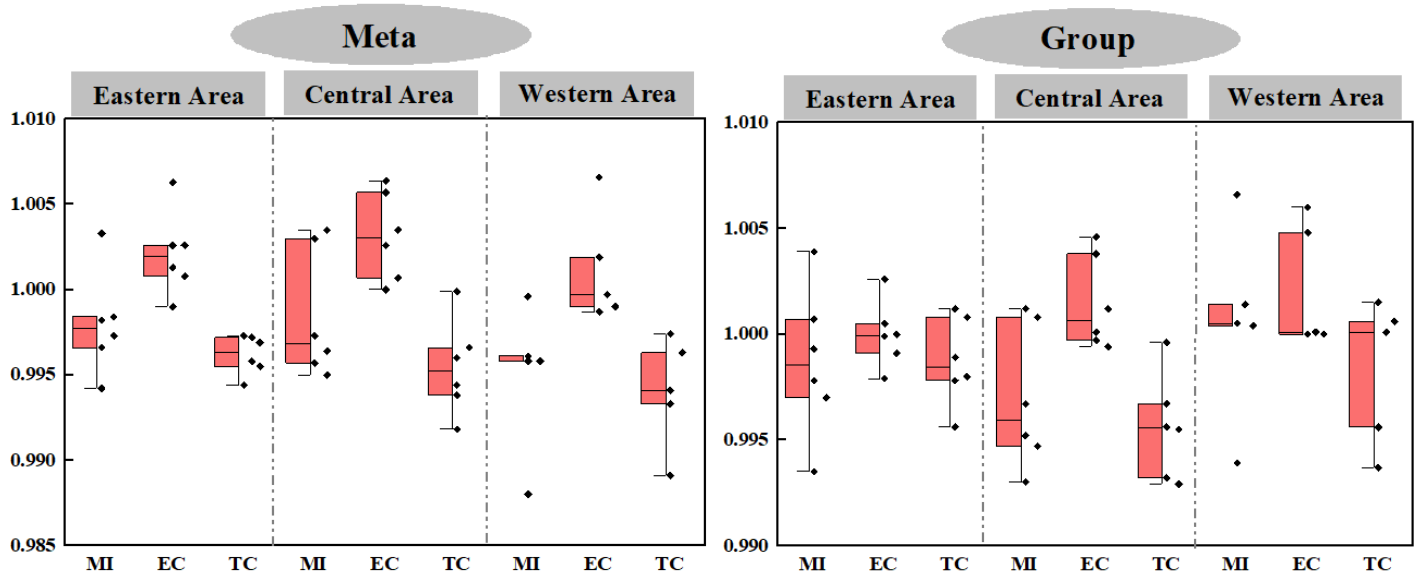

Fig.8. Average PBG and its decomposition target in three regions.

As shown in Fig.8, under the common frontier, the average annual PBG of eastern region, central region and western region is $0.9980,0.9985$ and 0.9951 , respectively. Under the regional frontier, the PBG of three regions are $0.9987,0.9969$ and 1.0006 , respectively. In the western region, the PBG is the lowest under the common frontier, and is the highest under the regional frontier. It is positive growth, indicating that the western region has more development potential and advantages when considering the regional factors.

The eastern region is mostly located in the plain areas of various river basins, with developed transportation, broad market and easy industrial agglomeration. At the same time, the more developed the economy is, the more bulk farming is replaced by large-scale farming. The transformation of production mode is more conducive to the rational use of existing resources, avoid unnecessary cost waste, and maximize profits and benefits. Guangdong Wen's Group occupies a relatively large market share in Chinese pig industry. Its livestock and poultry breeding business mainly focuses on raising pigs and chickens. The enterprise adopts the mode of "company + family farm" and implements the one-stop production and operation mode of whole management process of industrial chain. This makes Guangdong PBG ahead of the rest of the country. The development of pig breeding industry in the central region is slow, so the investment supported by the government is mainly concentrated in Henan, Liaoning, Heilongjiang, Jiangsu, Guangxi, Hebei and Shandong. The fluctuation of PBG is mainly caused by the fluctuation of technical progress index. The fluctuation of technical progress mainly fluctuates with the fluctuation of pig breeding industry, that is, the change of disease and pork price. According to the 

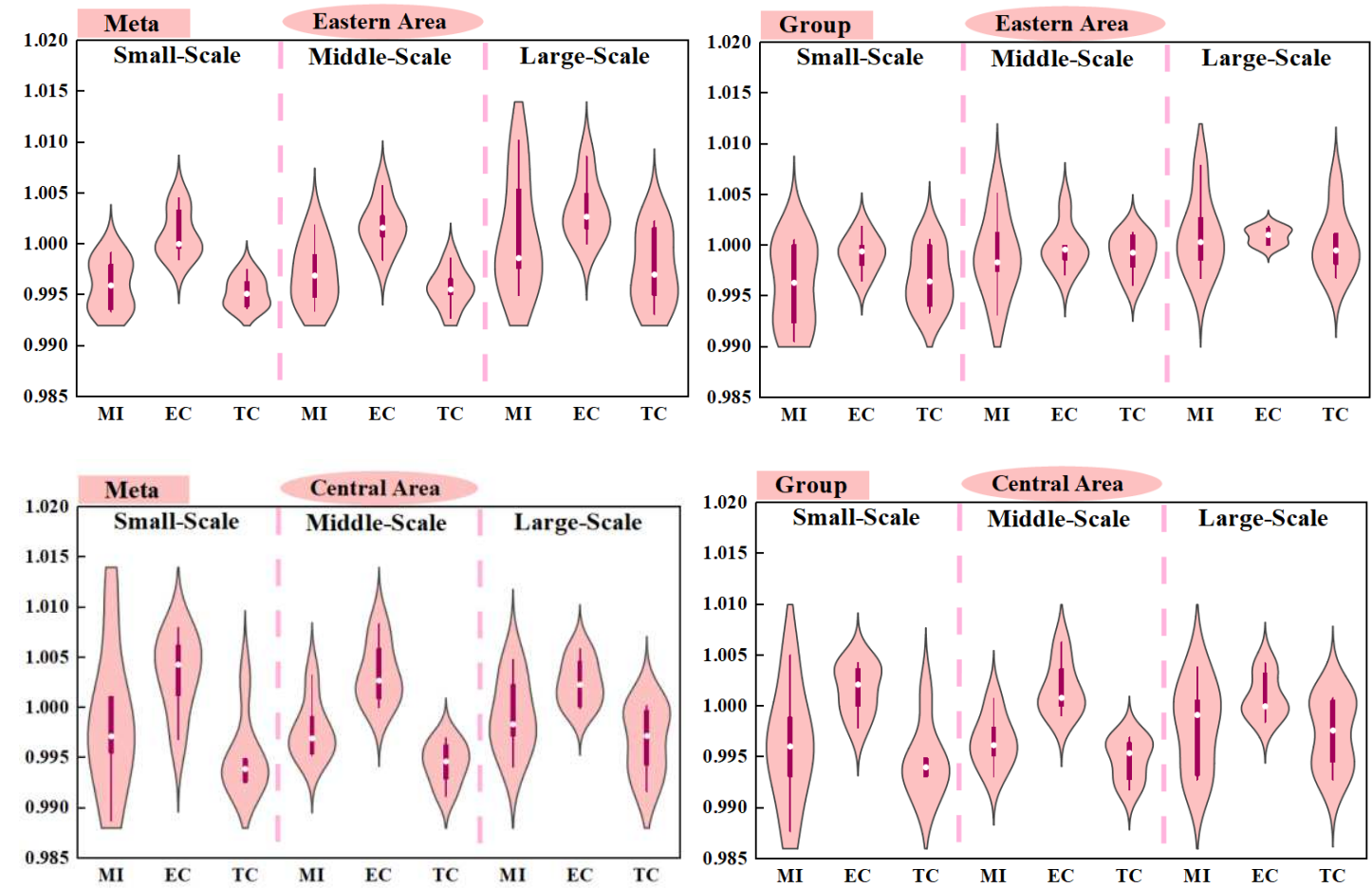

analysis of relevant statistical data, it is found that the fluctuation of PBG (technology progress index) has a relatively consistent fluctuation trend with the pork price. The reason is that when the pork market is good, large-scale pig farms have the incentive to research and introduce new technologies. Conversely, existing technologies may be idle.
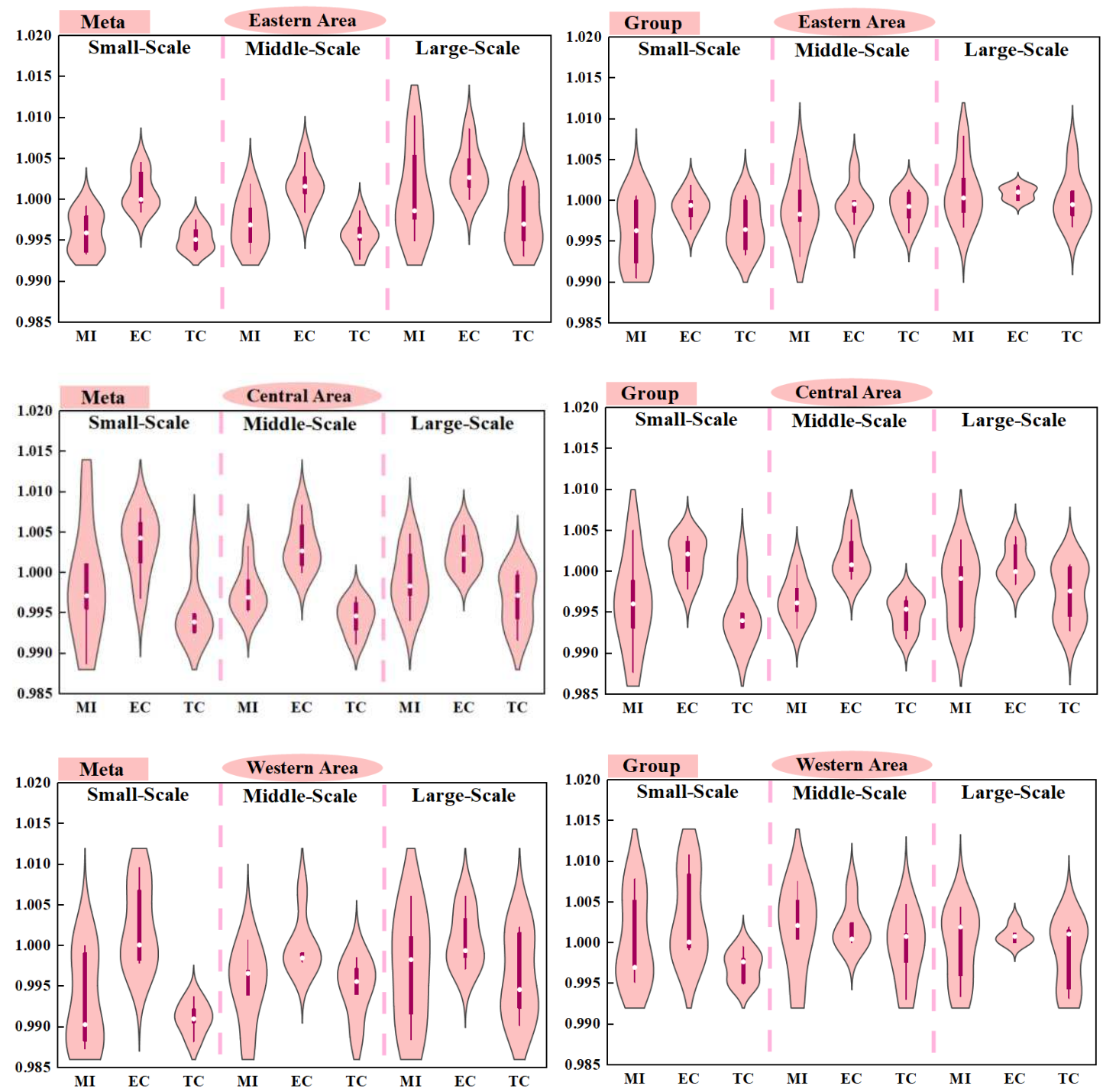

Fig.9. Different sized average PBG and its decomposition target in three regions.

As shown in Fig.9, under the metafrontier, the three-sized PBG in the eastern region are 0.9960, 0.9971 and 1.0009, respectively, in the central region are $0.9985,0.9978$ and 0.992 , respectively, and in the western region are $0.9930,0.9951$ and 0.9971 , respectively. The large-scale PBG in the eastern region is greater than 1 . The three scales of PBG in the central region and western region are less than 1. Under the group frontier, the PBGs of small, medium and large scale in the eastern region are 0.9960, 0.9989 and 1.0011, in the western region are 0.9961, 0.9965 and 0.9981, and in the western region are 1.0004, 1.0017 and 0.9996 . Similarly, the large-scale PBG in the eastern region is greater than 1, and the three scales in the central region are all less than 1. But the small-scale and medium-sized PBG in the western region are greater than 1 , indicating that in the case of considering regional factors, the western region has better development and pays more attention to the ecological effects. The natural breeding conditions in the western region of China are superior. At the same time, the large-scale PBG is higher than the 
medium-sized PBG and small-scale PBG, whether under the common frontier or the group frontier, whether in the eastern area, the central area or the western area.

Although the intensity of environmental regulation and pollution control investment in the eastern region are higher than those in the central region and western region, due to the relatively backward economic development in the western region, it is easy to select sites suitable for large-scale pig farm construction and less ecological environment damage in this region. In addition, the main environmental pollutants produced by pigs are feces and urine, while the western region is a large agricultural province with sparsely populated land, high forest coverage and large absorption of pollutants. Therefore, considering the regional heterogeneity, the average PBG in the western region is higher than that in the eastern region and central region, with a positive growth.

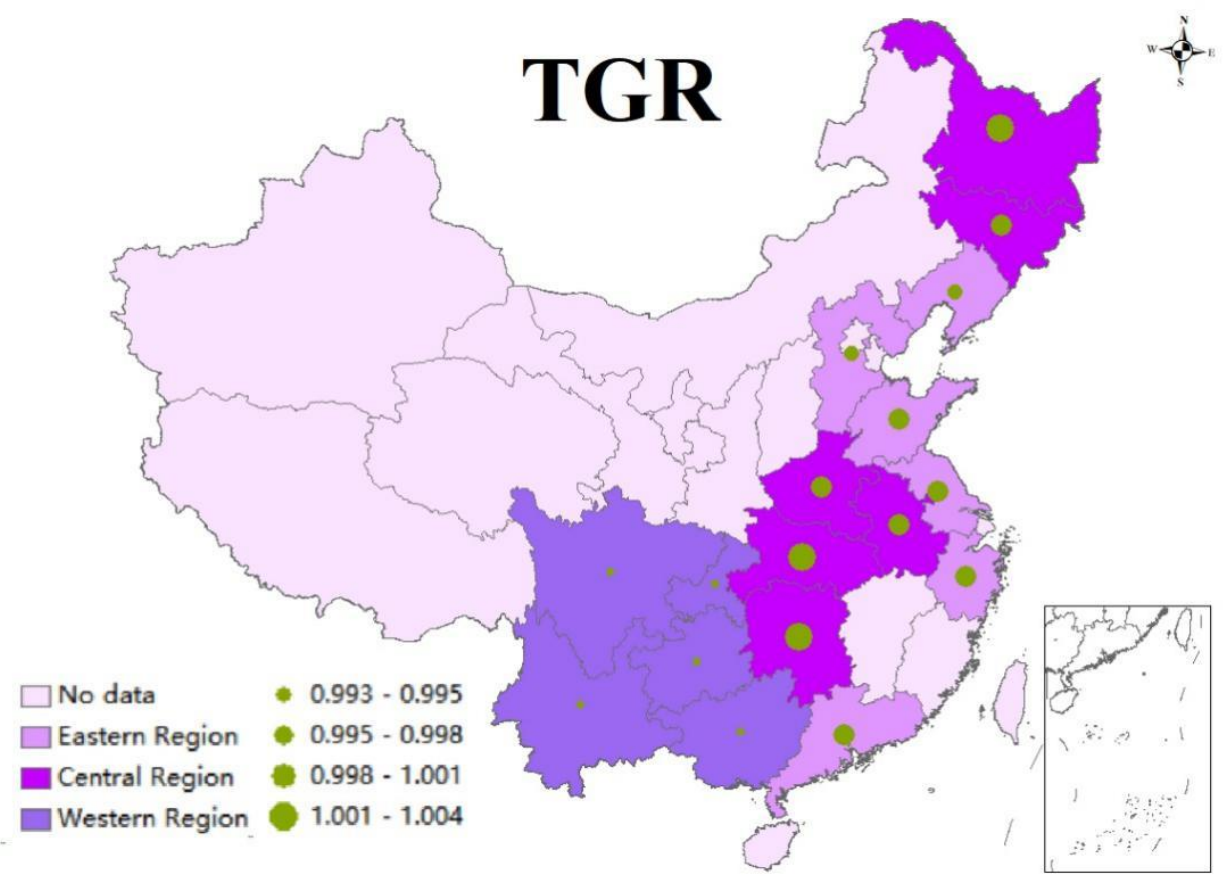

Fig.10. Average TGR in different regions.

As shown in Fig.10, the TGR of Jilin, Zhejiang and Jiangsu are all 1.0003, indicating that the gap with the metafrontier is only $0.03 \%$. The TGR of Guangdong was 0.9995 , and that of Anhui was 1.0005 , indicating that there was only a $0.05 \%$ gap with the common frontier. From the regional level, the TGR of the eastern region is 0.9993 , that of the central region is 1.0016 , and that of the western region is 0.9945 , all around 1 . The TGR of the western region is negative, showing that the western region has not reached the best frontier technology level, which is $0.55 \%$ lower than that of the common frontier. The TGR in the central region is greater than 1, indicating that the technology level of the central region is advanced, the promotion of low-carbon aquaculture technology is high, and the gap with the common frontier is $0.16 \%$. Although TGR in eastern China is negative, it is only $0.07 \%$ lower than the common frontier. This is in line with the actual situation in China, the western region is backward in economy, mainly in traditional pig breeding mode, and the level of clean farming technology is low. However, the central region and the eastern region are densely populated and have relatively developed economy, so there has the power to carry out technological innovation and improve management level. 


\section{Conclusions and policy recommendations:}

Based on the MinDW-MML model, this paper calculates the PBG under the common frontier and regional frontier of Chinese 17 provinces from 2004 to 2018, and decomposes it into TC and EC. The outcomes show that:

(1) Regardless of the common frontier or the group frontier, the PBG presents large spatial and temporal differentiation characteristics. Compared with the eastern region and central region, the western region has obvious advantages in PBG. The PBG of the three regions under the common frontier is 0.9980, 0.9985 and 0.9951, respectively. The regional frontiers are 0.9987, 0.9969 and 1.0006, respectively. Although the PBG of the western region is lower under the common frontier, the PBG is significantly higher than the other two regions considering the regional heterogeneity, and is greater than 1 .

(2) The overall PBG appears a downward trend, which is mainly due to the technical degradation. Pork price and disease lead to obvious fluctuation characteristics in PBG and TC indices. The significant fluctuation of PBG in 2007 indicated that the pig epidemic prevention and control situation and the stability of the market had an essential impact on the pig production level.

(3) Compared with small-scale and medium-sized PBG, large-scale PBG has apparent advantages. The PBGs of the three scales under the common frontier are 0.9960, 0.9968 and 0.9992 , respectively. And the group frontiers are 0.9974, 0.9989 and 0.9996, respectively. It highlights the important role of scale advantage in China's pig breeding industry.

According to the current situation of China's pig industry, the following policy implications are put forward:

(1) Make full use of geographical and natural conditions and attach importance to the development of pig breeding in the western region. The western region of China has vast land and sparsely populated. The natural environment conditions are fantastic. The region with higher PBG have higher environmental control cost of cultivated land. The western region in the deep inland can give priority to the development of large-scale pig breeding, while the central region needs to overcome the natural conditions to develop scale breeding. The eastern region should consider importing more pigs from other regions or building breeding bases in foreign ports under the condition of meeting certain pork guarantee rate in this region.

(2) Increase the research and introduction of pig breeding clean technology, and improve the application efficiency. It is necessary to think highly of the prevention and control of pig diseases and stabilize the pork price. The government should strengthen the implementation of environmental protection policies and related laws and regulations, and enhance the promotion of environmental protection technology in pig breeding. With the increasing pressure on environmental problem, retail farming will accelerate the exit from the market. In this way, in addition to reducing the market live pig supply, it can also make the industry transition to specialization and scale. At the same time, the decrease of the proportion of individual farms makes the industry concentration increased, which is more conducive to improve the technical application ability of technology absorption side, and accelerate the update speed of new technology of Chinese rural pig breeding.

(3) Vigorously develop large-scale pig breeding, and gradually realize the transformation from scattered farming to large-scale breeding. Under the influence of price fluctuations and other factors, large-scale farms and group farming still have profits, while small-scale farmers and secondary fattening households are relatively not optimistic, and will suffer losses, which is the law of natural elimination of the market. Large scale breeding plays an extremely important role in coming true the industrialization 
of pig breeding, improving hog production efficiency and meeting people's meat demand from both technological progress and industrial development.

\section{Ethics approval and consent to participate}

Not applicable.

\section{Consent for publication}

Not applicable.

\section{Availability of data and materials}

The datasets generated and analysed during the current study are available in the 《National Compendium of Agricultural Product Expenses-Benefit Data》 and 《Discharge Coefficient Manual》 released by the Office of the First National Pollution Source Census Leading Group. https://data.cnki.net/yearbook/Single/N2019120280. https://wenku.baidu.com/view/9f82b6740342a8956bec0975f46527d3250ca66c.html.

\section{Competing interests}

The authors declare that they have no competing interests.

\section{Funding}

This research was funded by the National Social Science Foundation Program of China (19BJY104).

\section{Authors' contributions}

ZS was responsible for the definition of conceptualization and methodology, and the use of software. LJW analyzed and interpreted the data, and was a major contributor in writing- original draft. ZDH was responsible for the supervision and writing- reviewing. All authors read and approved the final manuscript.

\section{References}

Abdalla CW, Lanyon LE, Hallberg MC (1995) What we know about historical trends in firm location decisions and regional shifts: policy issues for an industrializing animal sector. American Journal of Agricultural Economics 77:1229-1236.

Adams PL, Daniel TC, Edwards DR, Nichols DJ, Pote DH, Scott HD (1994) Poultry litter and manure contributions to nitrate leaching through the Vadose Zone. Soil Science Society of America Journal 58:1206-1211.

Ali MH, Shui LT, Yan KC, Eloubaidy AF, Foong KC (2000) Modeling water balance components and irrigation efficiencies in relation to water requirements for double-cropping systems. Agricultural water management 46:167-182.

Apostolopoulos CD, Theodoropoulou H, Petrakos G, Theodorpoulos G (2001) Factors affecting the regional pig meat productivity of commercial pig units in Greece. Agricultural Economics Review 2:3946.

Briec W (1999) Holder distance function and measurement of technical efficiency. Journal of Productivity Analysis 11:111-131.

Burkholder JA, Libra B, Weyer P, et al. (2007) Impacts of waste from concentrated animal feeding 
operations on water quality. Environmental Health Perspectives 115:308.

Campagnolo ER, Johnson KR, Karpati A, et al. (2002) Antimicrobial Residues in Animal Waste and Water Resources Proximal to Large-scale Swine and Poultry Feeding Operations. Science of the Total Environment 299:89-95.

Charnes A, Rousseau JJ, Semple JH (1996) Sensitivity and stability of efficiency classifications in data envelopment analysis. Journal of Productivity Analysis 7:5-18.

Chung YH, Fare R, Grosskopf S (1997) Productivity and undesirable outputs: A directional distance function approach. Journal of Environmental Management 51:229-240.

Fraison HB, Guilpain P, Schiffmann A, et al. (2013) Pulmonary cryptococcosis in a patient with Crohn's disease treated with prednisone, azathioprine and adalimumab: exposure to chicken manure as a source of contamination. Journal of Crohns and Colitis 7:e11-e14.

Du HM, Li MR, Wang MC (2017) Spatial-temporal differences in environmental efficiency of scale pig breeding in China based on SE-DEA model. Chinese Journal of Animal Science. 53: 131-137 (In Chinese).

Ernst D (1998) Catching-up, crisis and industrial upgrading: evolutionary aspects of technological learning in Korea's electronics industry. Asia Pacific Journal of Management 15:247-283.

Evans PO, Westerman PW, Overcash MR (1984) Subsurface drainage water quality from land application of seine lagoon effluent. Transactions of the American Society of Agricultural and Biological Engineers 27:473-480.

Falavigna G, Manello A, Pavone S (2013) Environmental efficiency, productivity and public funds: the case of the Italian agricultural industry. Agricultural Systems 121:73-80.

Guevarra RB, Lee JH, Lee SH, Seok MJ, Kim DW, Kang BN, Johnson TJ, Isaacson RE, Kim HB (2019) Piglet gut microbial shifts early in life: causes and effects. Journal of Animal Science and Biotechnology 10:519-528.

Humphrey J, Schmitz H (2010) How does insertion in global value chains affect upgrading in industrial clusters. Regional Studies 36:1017-1027.

Kaneko S, Tanaka K, Toyota T, Managi S (2004) Water efficiency of agricultural production in China: regional comparison from 1999 to 2002. International Journal of Agricultural Resources Governance and Ecology 3:231-251.

Kaplinsky R (2014) Spreading the gains from globalization: what can be learned from value-chain analysis? Problems of Economic Transition 10:74-115.

Key N, McBride WD (2008) Technology, large farm size increased productivity on U.S. hog farms. Amber Waves 6:16-21.

Kliebenstein J, Larson B, Honeyman M, Penner A (2003) A Comparison of Production Costs, Returns and Profitability of Swine Finishing Systems. Iowa State University.

Leng BB, Gong J, Zhang WB, Ji XQ (2017) Study on the measurement and calculation of environmental pollution bearing index of China's pig scale. IOP Conference Series: Earth and Environmental Science 94:012-052.

Lilienfeld A, Asmild M (2007) Estimation of excess water use in irrigated agriculture: a data envelopment analysis approach. Agricultural water management 94:73-82.

Managi S, Kaneko S (2006) Economic growth and the environment in China: an empirical analysis of productivity. International Journal of Global Environmental Issues 6:89-133.

Mei G, Gan J, Zhang N (2015) Metafrontier environmental efficiency for China's regions: a slack-based efficiency measure. Sustainability 7:4004-4021.

Njuki E, Bravo-Ureta BE, Mukherjee D (2016) The good and the bad: Environmental efficiency in 
northeastern U.S. dairy farming. Agricultural and Resource Economics Review 45:22-43.

Oh DH (2010) A Global Malmquist-Luenberger Productivity Index. Journal of Productivity Analysis 34:183-197.

Onyenweaku CE, Effiong EO (2005) Technical efficiency in pig production in Akwa Ibom State, Nigeria. International Journal of Agriculture and Rural Development 6:51-57.

Paul D.Soloway (2004) Have hog producers with production contracts maintained an economic advantage of independent hog producers in recent years? May 15.

Petrovska M (2011) Efficiency of pig farm production in the Republic of Macedonia: data envelopment analysis approach. Swedish University of Agricultural Sciences Faculty of Natural Resources and Agricultural Sciences Department of Economics. Master's thesis 708:1401-4084.

Piot-Lepetit I, Moing ML, Bonneau M, et al. (2005) Productivity growth, technology progress and efficiency change in the French pig sector from 1996 to 2001. Post-Print. Hal-02290717, HAL.

Qiao FB, Chen J, Carter Colin, Huang JK, Rozelle S (2011) Market development and the rise and fall of backyard hog production in China. The Developing Economics 49:203-222.

Segerson K (1998) Uncertainty and incentives for nonpoint pollution control. Journal of Environmental Economics and Management 15:88-98.

Shortle JS, Horan R, Abler D (1998) Research issues in nonpoint pollution control. Environmental and Resource Economics 11:571-585.

Simar L, Wilson PW (1998) Sensitivity analysis of efficiency scores: how to bootstrap in non-parametric frontier models. Management Science 44:49-61.

Simar L, Wilson, PW (2000) A general methodology for bootstrapping in non-parametric frontier models. Journal of Applied Statistics 27:779-802.

Sueyoshi T, Goto M (2012) Efficiency-based rank assessment for electric power industry: A combined use of data envelopment analysis (DEA) and DEA-discriminant analysis (DA). Energy Economics 34:634-644.

Wang HS, Shen JH, Pi Y, Gao K, Zhu WY (2020) Low-protein diets supplemented with casein hydrolysate favor the microbiota and enhance the mucosal humoral immunity in the colon of pigs. Journal of Animal Science and Biotechnology 11:157-168.

Wang L, Chen Z, Ma D, et al. (2013) Measuring carbon emissions performance in 123 countries: application of minimum distance to the strong efficiency frontier analysis. Sustainability 5: 5319-5332. Wang XL, Adamou D, Chen YQ, Sui P, Gao WS, Jia LH (2015) Sustainability evaluation of the largescale pig farming system in north China: an energy analysis based on life cycle assessment. Journal of Cleaner Production. 102:144-164.

Wang XL, Wu X, Yan P, Gao WS, Chen YQ, Sui P (2016) Integrated analysis on economic and environmental consequences of livestock husbandry on different scale in China. Journal of Cleaner Production 119:1-12.

Wopke vander werf (2007) The locational determinants of large livestock operations: Evidence from the U.S. hog, dairy, and fed-cattle sectors. Selected paper prepared for presentation at the American Agricultural Economics Association Annual Meeting, Denver, Colorado, July.

World development report 2015: The changing nature of work. Washington D.C.: World Bank, 2015. Wu S, Walker D, Devadoss S, Lu YC (2002) Productivity growth and its components in Chinese agriculture after reforms. Review of Development Economics 5:375-391.

Xiao HB, Wang JM, Oxley L (2012) The evolution of hog production and potential sources for future growth in China. Food Policy 37:366-377. 
Yu YT, Huang JH, Zhang N (2019) Modeling the eco-efficiency of Chinese prefecture-level cities with regional heterogeneities: A comparative perspective. Ecological Modelling 402:1-17.

Yuan B, Ren S, Chen X (2017) Can environmental regulation promote the coordinated development of economy and environment in China's manufacturing industry? - a panel data analysis of 28 sub-sectors. Journal of Cleaner Production 149:11-24.

Yue L, Wu C, Zhang M (2014) Research on the evaluating method of non- renewable energy efficiency based on China's provincial data: green growth perspective. Applied Mechanics and Materials 733:303308.

Yue S, Yang Y, Pu Z (2017) Total-factor ecology efficiency of regions in China. Ecological Indicators 73:284-292.

Zhang N, Kong F, Yu Y (2015) Measuring ecological total-factor energy efficiency incorporating regional heterogeneities in China. Ecological Indicators 51:165-172.

Zhang J, Liu Y, Chang Y, Zhang L (2016) Industrial eco-efficiency in China: a provincial quantification using three-stage data envelopment analysis. Journal of Cleaner Production 143: 238-249.

Zhao LG, Lin J, Zhu JM (2015) Green total factor productivity of hog breeding in China: Application of SE-SBM model and grey relation matrix. Polish Journal of Environmental Studies 24:403-412.

Zhou JB, Jiang MM, Chen GQ (2007) Estimation of methane and nitrous oxide emission from livestock and poultry in China during 1949-2003. Energy Policy 35:3759-3767.

Zhou P, Ang BW, Poh KL (2006) Slacks-based efficiency measures for modeling environmental performance. Ecological Economics 60:111-118.

Zuo YY, Peng J, Feng YG (2016) The study on total factor productivity of scale pig breeding under environmental constraints. Rural Economy 9:37-43(In Chinese). 
Figures
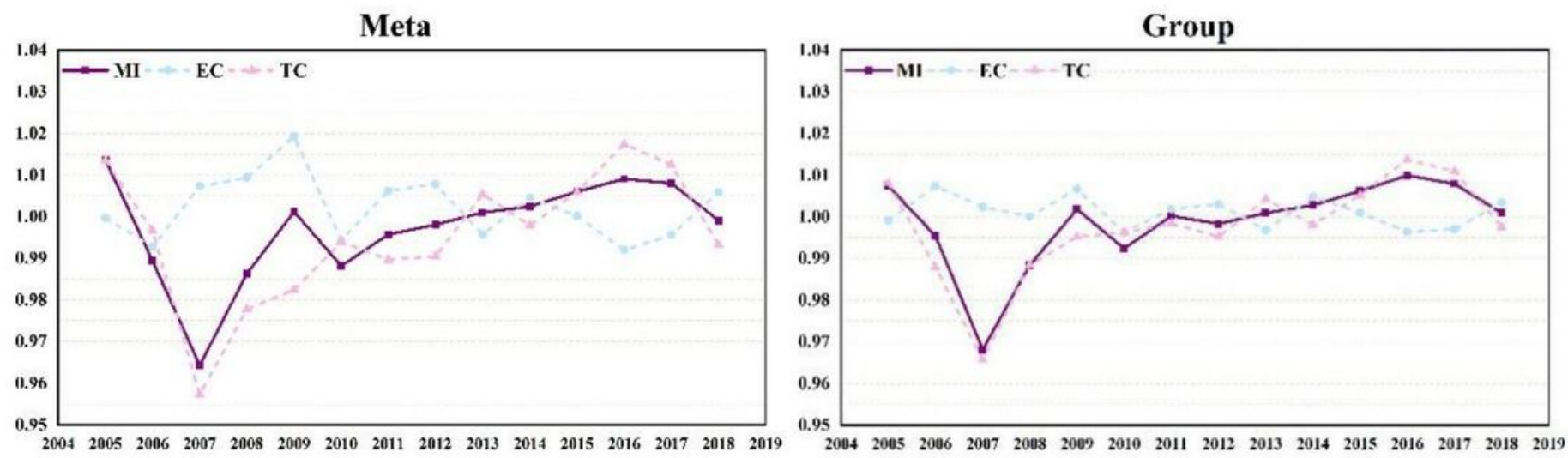

Figure 1

China's PBG and its decomposition target during 2004-2018. 


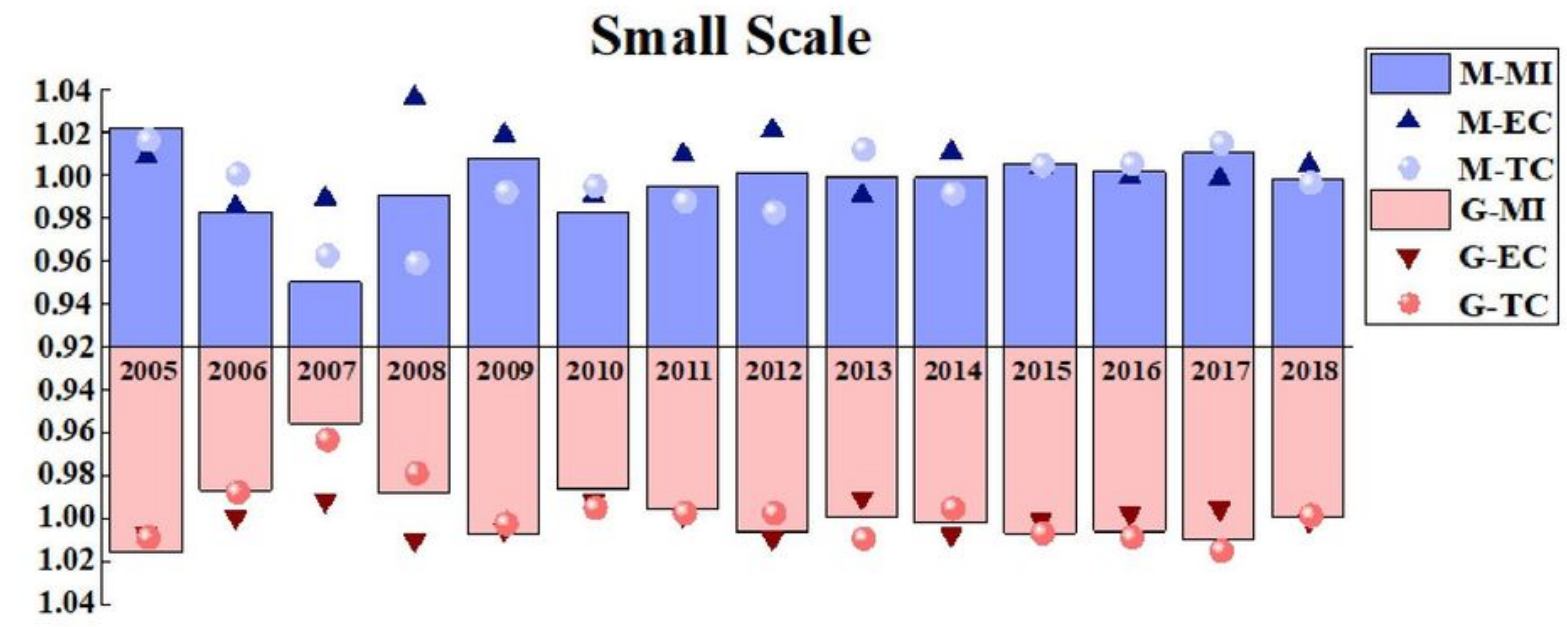

Middle Scale

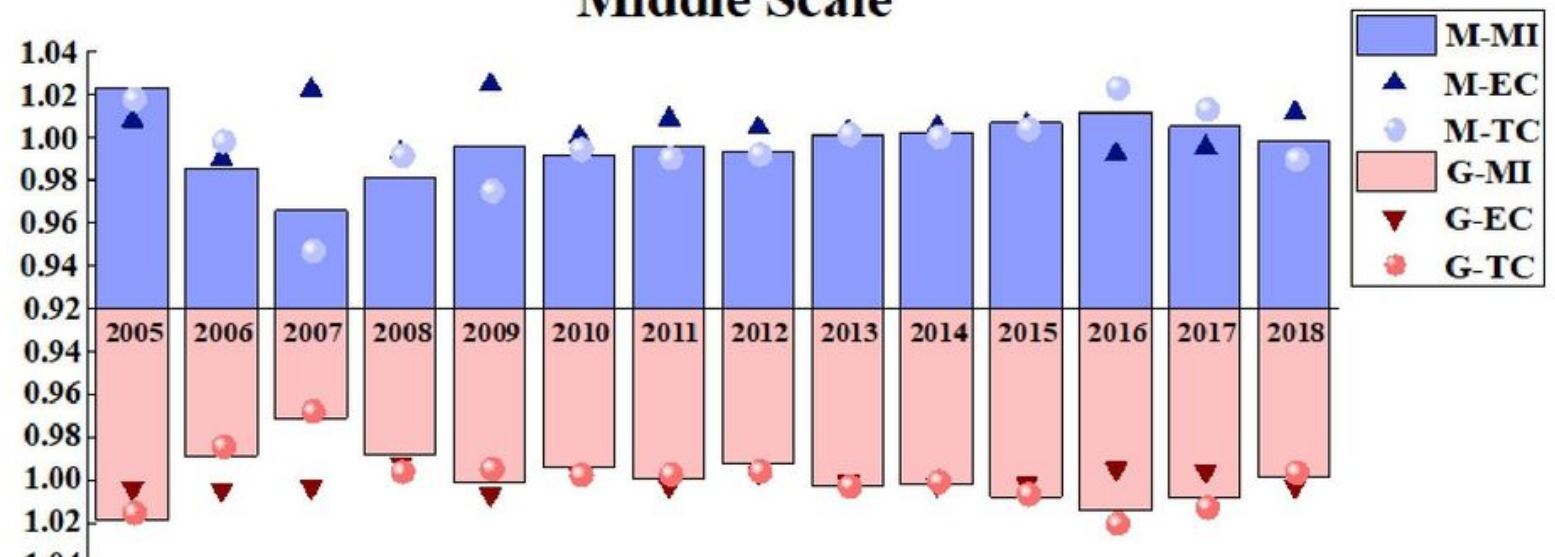

1.04

Large Scale

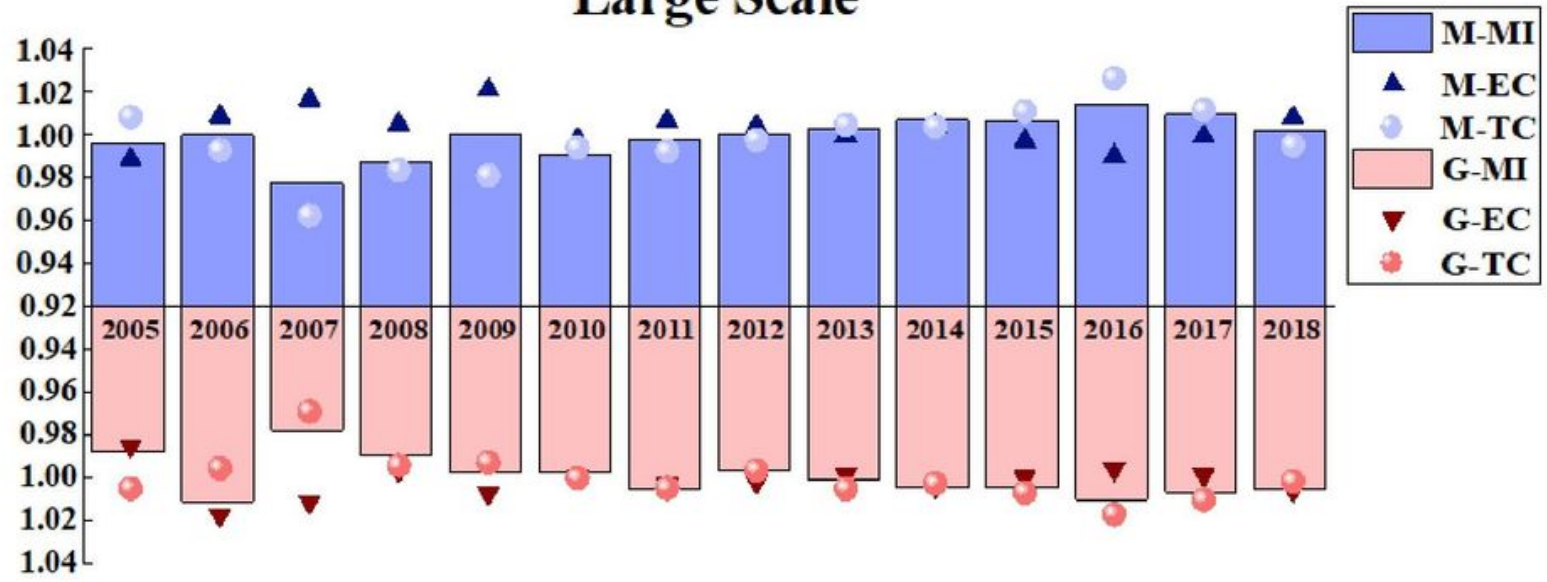

Figure 2

China's various-sized PBG and its decomposition target during 2004-2018. 

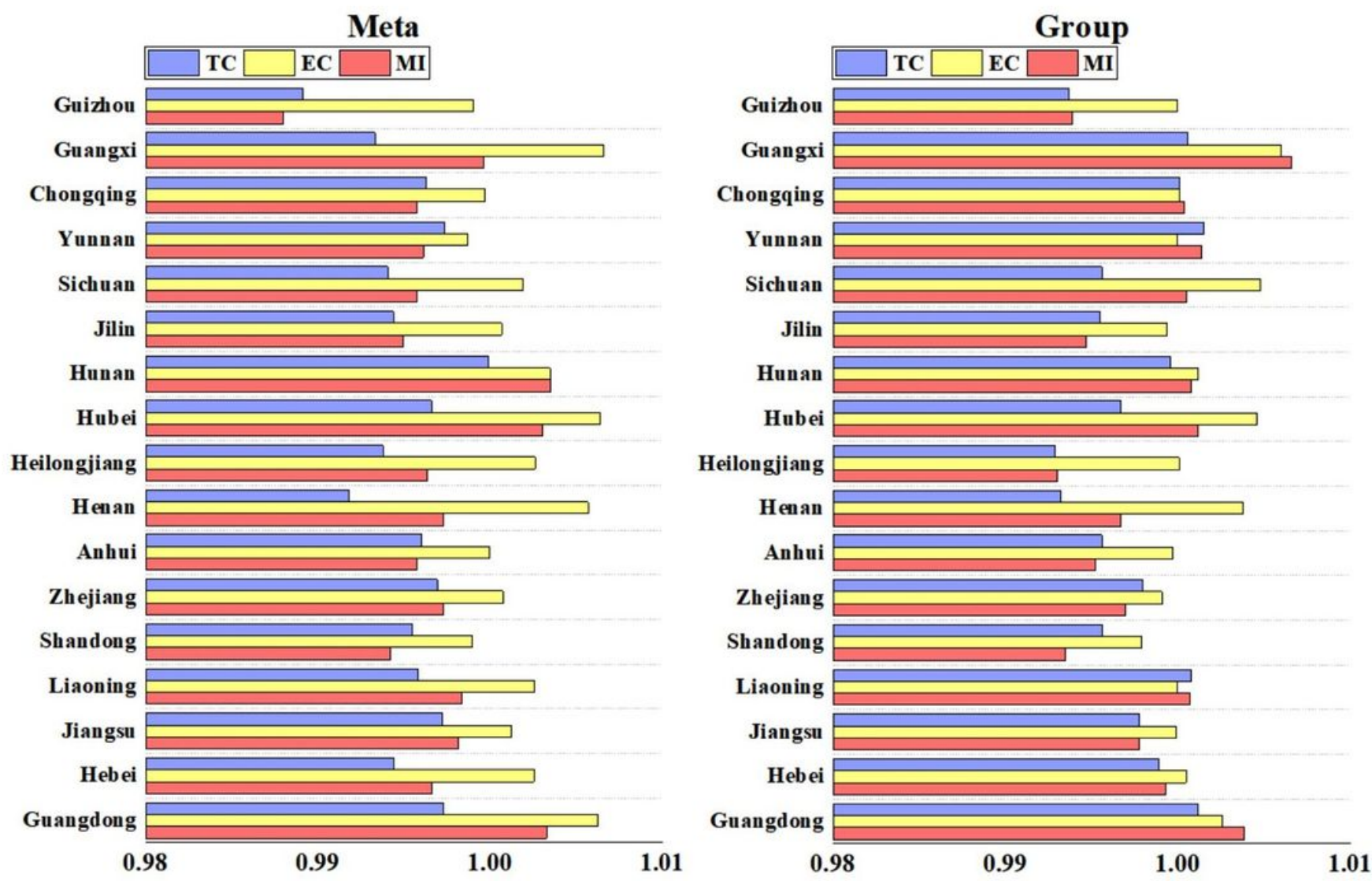

Figure 3

PBG and its decomposition target in different provinces. 

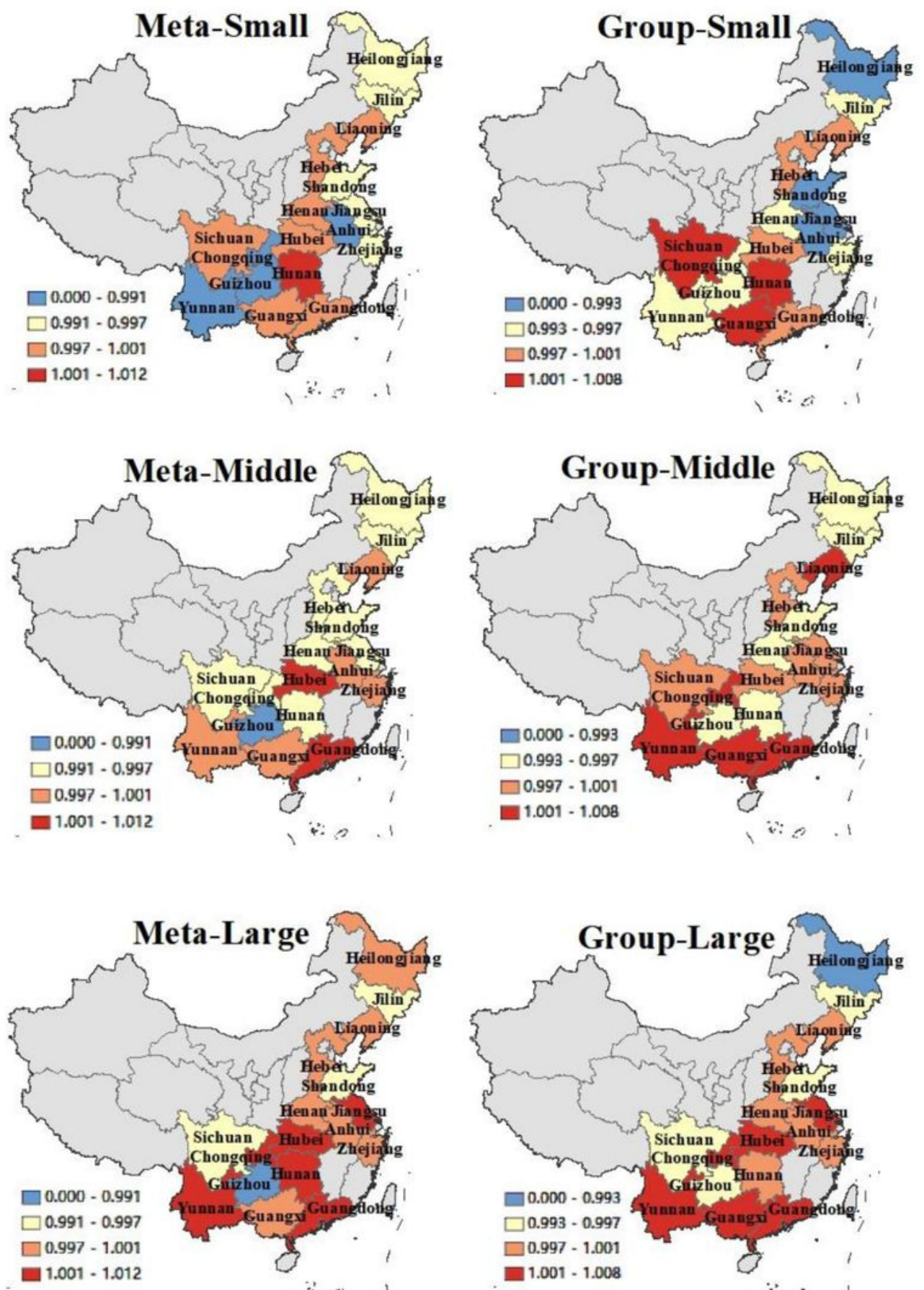

\section{Figure 4}

Various-scaled PBG in different provinces Note: The designations employed and the presentation of the material on this map do not imply the expression of any opinion whatsoever on the part of Research Square concerning the legal status of any country, territory, city or area or of its authorities, or concerning the delimitation of its frontiers or boundaries. This map has been provided by the authors. 
TGR

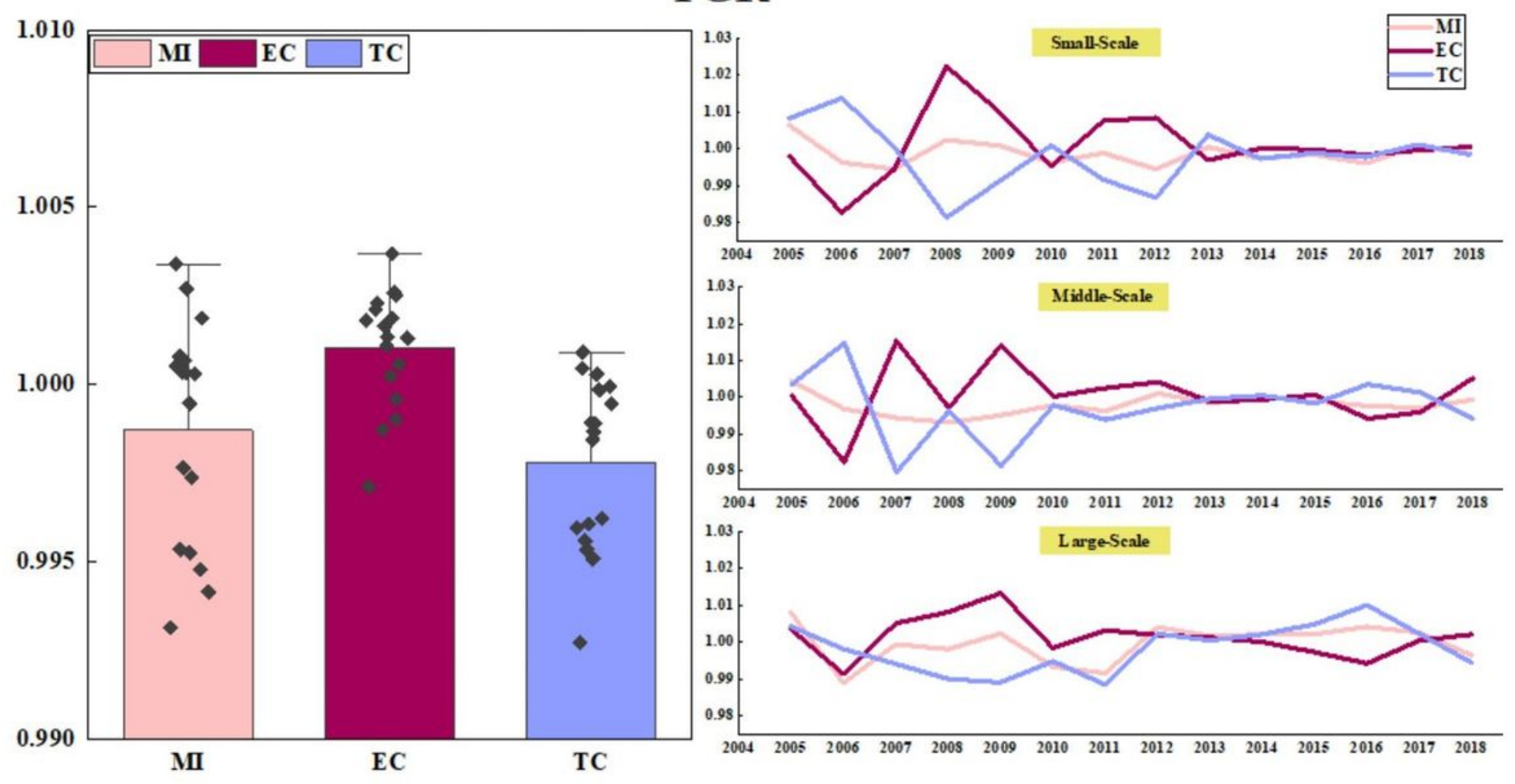

Figure 5

TGR in general and different scale during 2004-2018. 

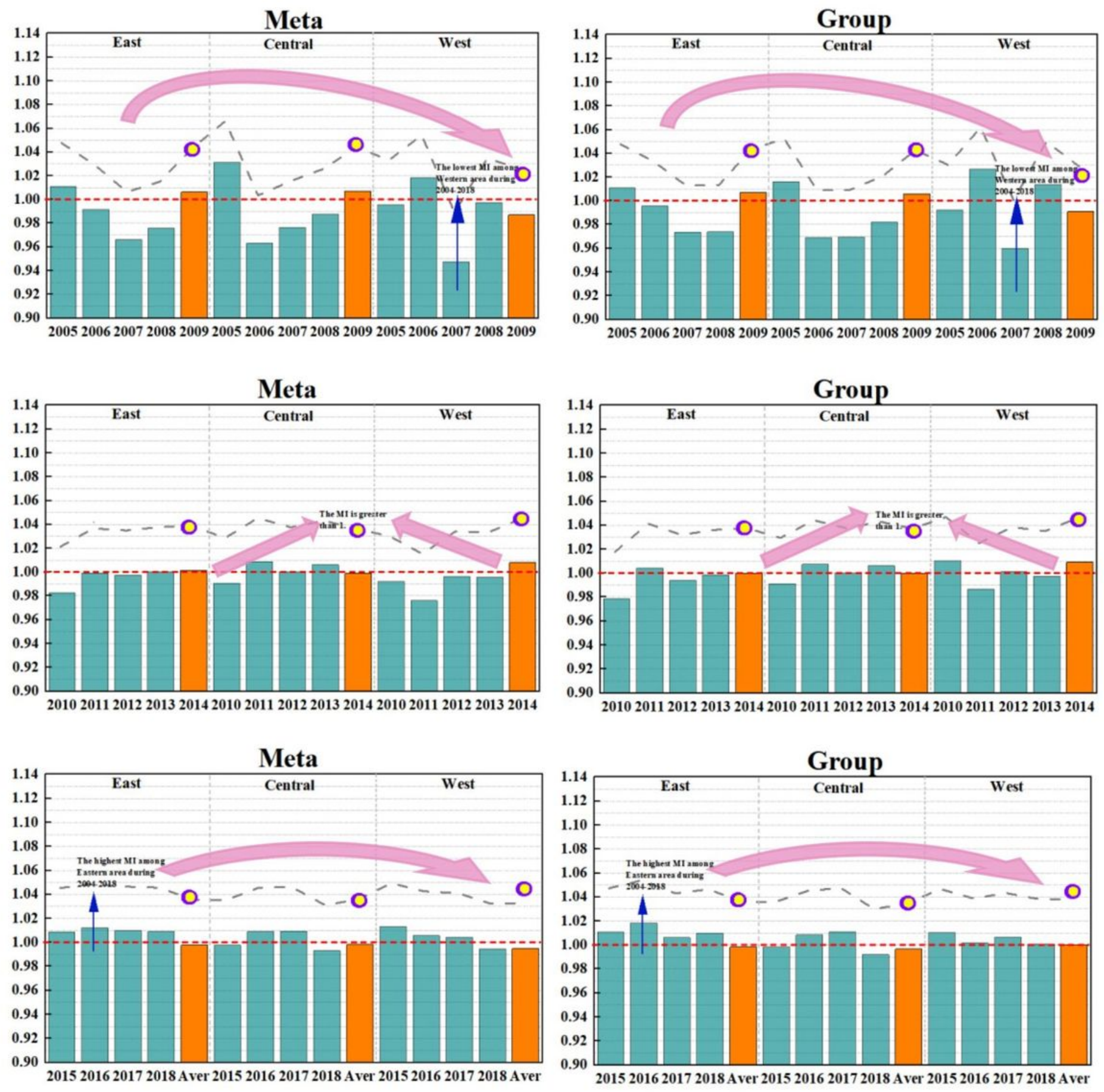

Figure 6

PBG in three regions during 2004-2018 

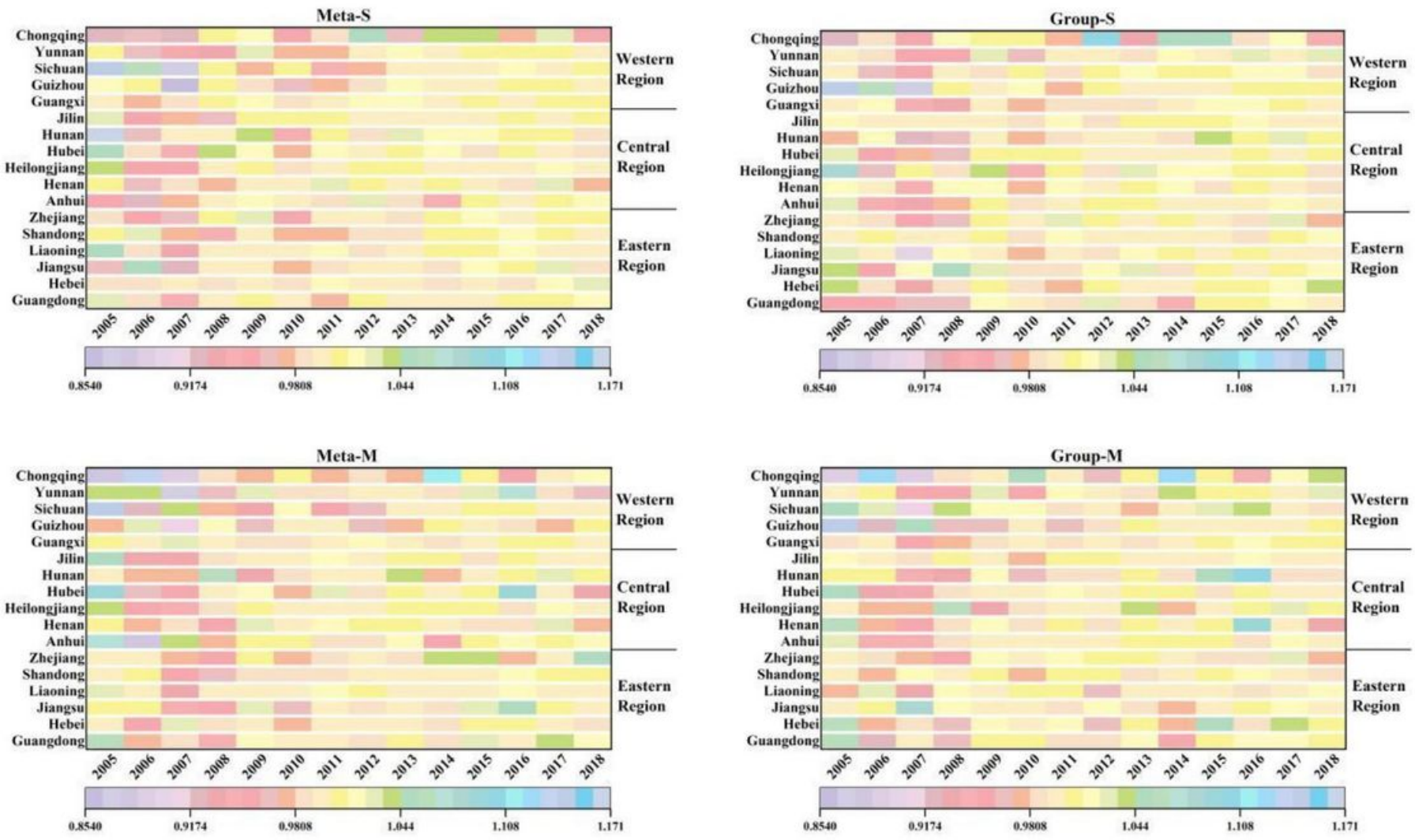

Meta-L.
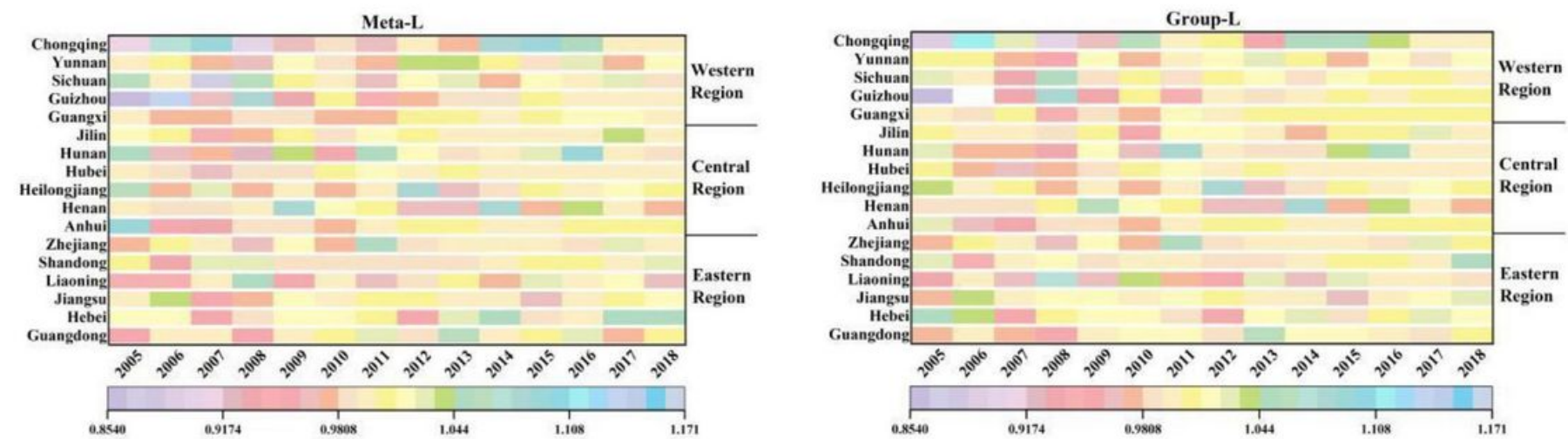

Figure 7

Three-sized PBG in three regions during 2004-2018. 


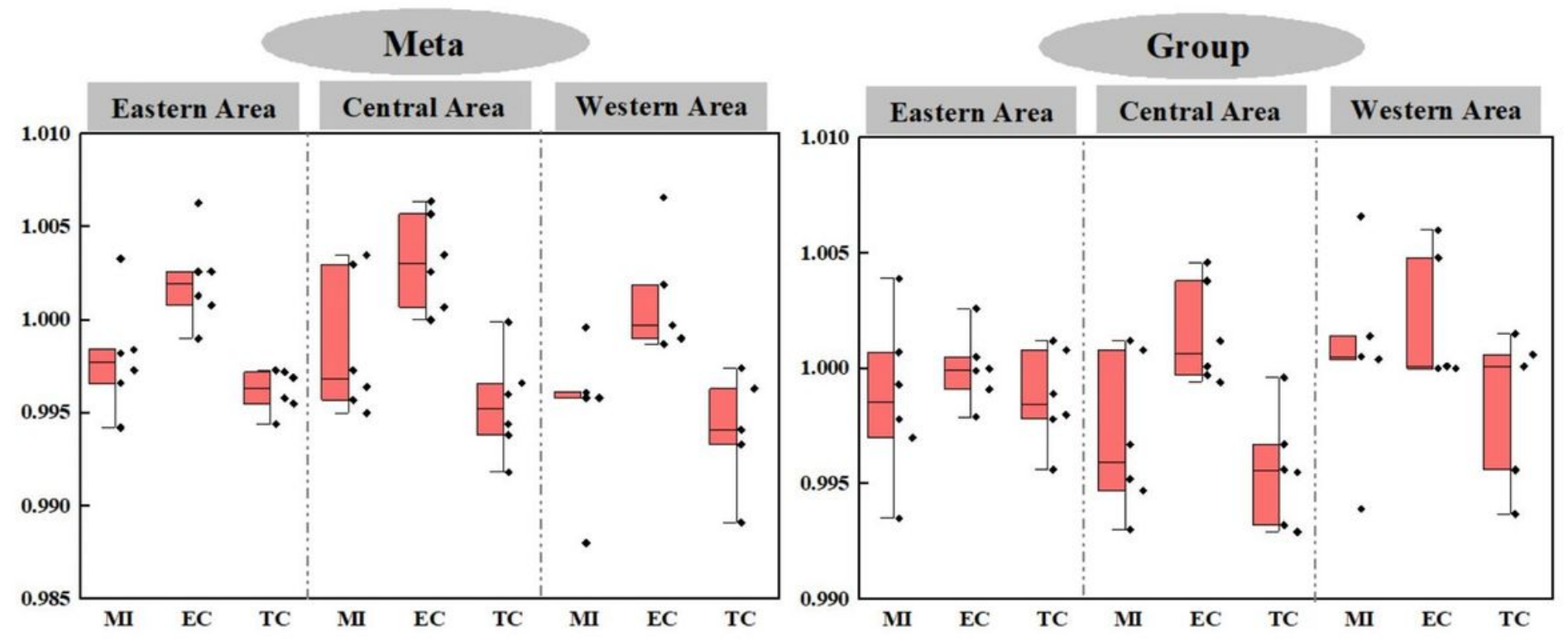

Figure 8

Average PBG and its decomposition target in three regions. 

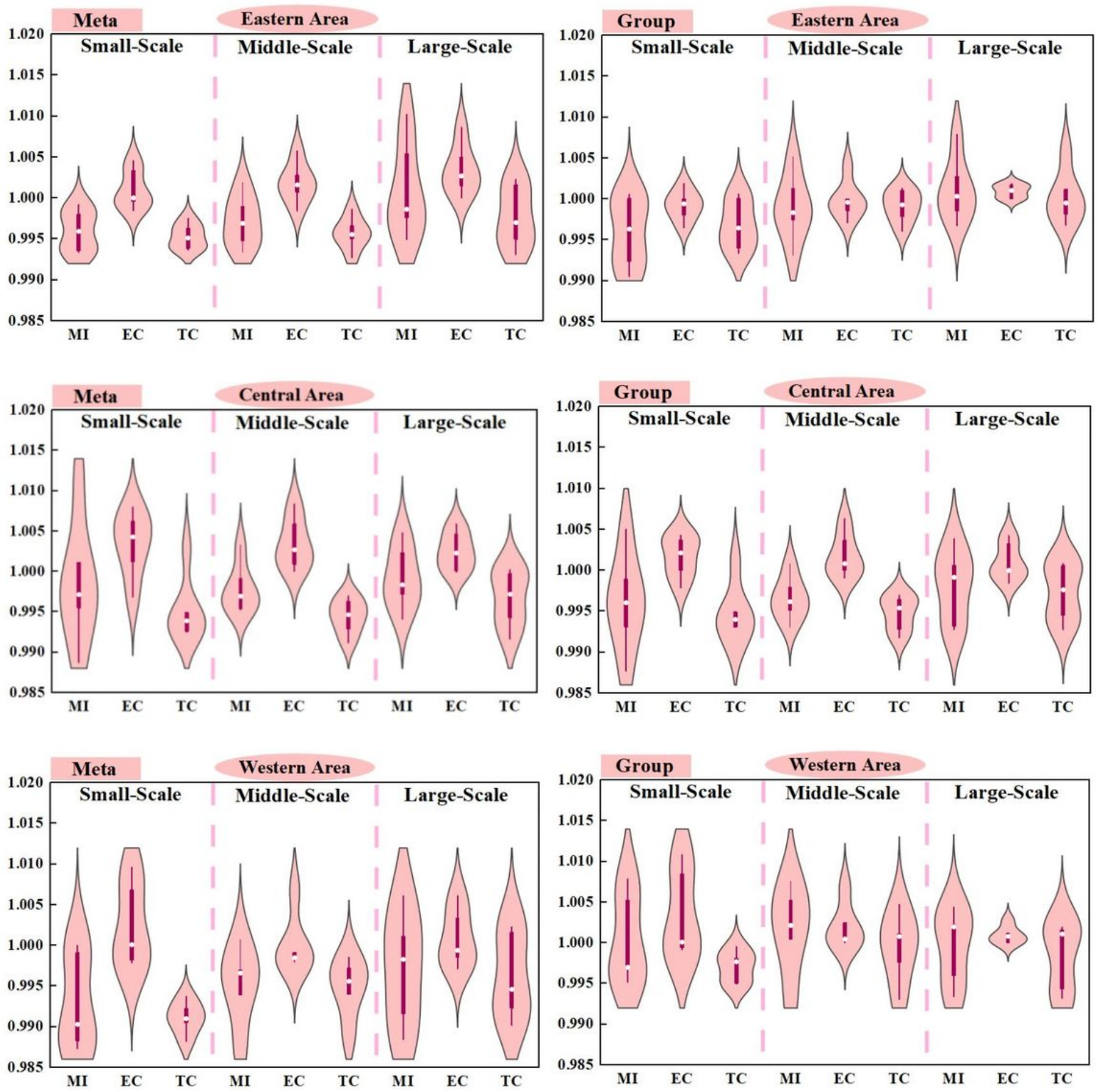

Figure 9

Different sized average PBG and its decomposition target in three regions. 


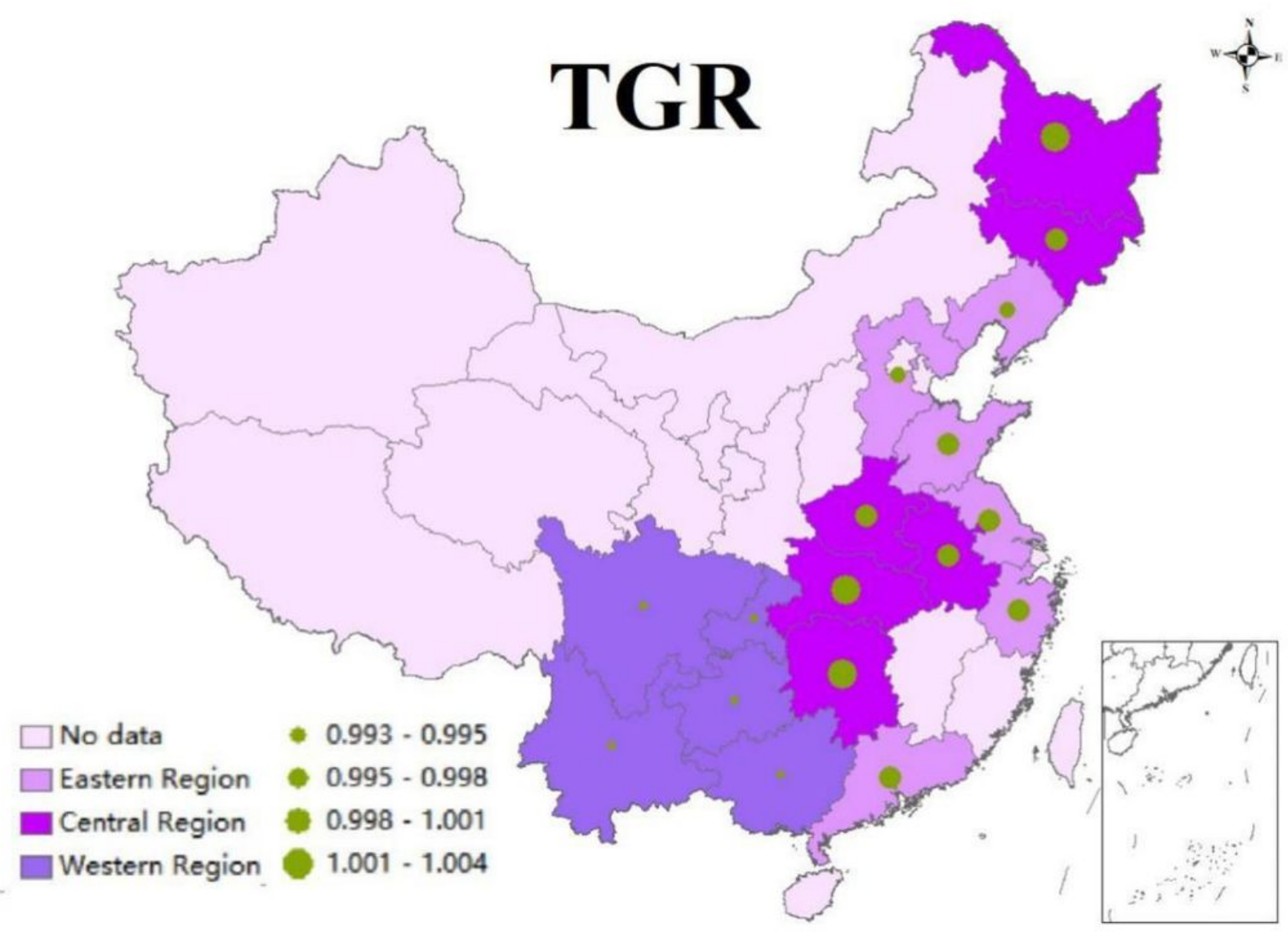

\section{Figure 10}

Average TGR in different regions. Note: The designations employed and the presentation of the material on this map do not imply the expression of any opinion whatsoever on the part of Research Square concerning the legal status of any country, territory, city or area or of its authorities, or concerning the delimitation of its frontiers or boundaries. This map has been provided by the authors. 